\title{
Towards a Relativized Concept of Cyclic Linearization
}

\author{
Gereon Müller
}

\section{Introduction}

Suppose that a grammar is an optimal satisfaction of requirements imposed by the interfaces LF and PF (see Chomsky (2000, 2001b, 2005a)). ${ }^{1}$ Against this background, Fox and Pesetsky (2003, 2005a,b)) discuss a number of phenomena involving shape conservation effects with movement operations. They suggest that these effects should not be accounted for by invoking specific constraints demanding just that (as, e.g., in Müller (2001), Williams (2003)), or by syntax-internal constraints (like the Minimal Link Condition, as in Collins and Thráinsson (1996)). Rather, they should be taken to follow from an independently motivated system of cyclic linearization applying to local spell-out domains (phases). The present paper is an attempt to revise Fox \& Pesetsky's system. More specifically, I will try to substantiate the following three claims. First, a cyclic linearization approach to shape conservation effects is in principle worth pursuing. Second, the specific cyclic linearization approach developed by Fox \& Pesetsky faces certain empirical and conceptual problems. And third, these problems can be avoided if cyclic linearization is assumed to be relativized rather than rigid, and if more emphasis is placed on the derivational nature of the system. ${ }^{2}$

I will proceed as follows. In section 2, I outline the main features of Fox \& Pesetsky's cyclic linearization approach. In section 3, I present a num-

\footnotetext{
${ }^{1}$ For helpful comments, I would like to thank Petr Biskup, Gisbert Fanselow, Kleanthes Grohmann, Fabian Heck, Gunnar Hrafn Hrafnbjargarson, Jóhannes Gísli Jónsson, Denisa Lenertová, David Pesetsky, Wolfgang Sternefeld, and particularly Hans-Martin Gärtner, as well as the audiences of the ZAS workshop Interfaces + Recursion = Language? in March 2005 in Berlin, the InterPhases Conference in May 2006 at the University of Cyprus, and the Norms workshop on Verb Placement in January 2007 at the University of Iceland. I alone am responsible for any misunderstandings and errors.

${ }^{2}$ The concept of relativized cyclic linearization as an alternative to rigid cyclic linearization is inspired by a predecessor in the domain of locality theory, viz., relativized minimality (see Rizzi (1990), Fanselow (1991)) as an alternative to rigid minimality (cf. Chomsky (1986), Baker (1988)).
} 


\section{Gereon Müller}

ber of empirical and conceptual problems raised by this approach. The conclusion is that a theory of cyclic linearization should rely on (i) a strictly derivational organization of grammar, (ii) a relativization of ordering statements that are sensitive to two fundamentally different kinds of Merge operation (feature-driven vs. non-feature-driven), and (iii) a principled theory of successive-cyclic movement that incorporates the distinction among Merge operations. Section 4 then sketches such an approach to successive-cyclic movement along these lines (based on Heck and Müller (2000, 2006a)), as a prerequisite for a new approach to cyclic linearization. Finally, section 5 develops such an approach: a strictly derivational system of relativized linearization.

\section{Cyclic Linearization}

\subsection{Basic Assumptions}

Fox and Pesetsky $(2003,2005 a, b)$ adopt a number of basic minimalist assumptions. For instance, syntactic structure is created incrementally, bottomup, by alternating applications of external and internal Merge (i.e., Merge and Move, respectively) (see Chomsky $(1995,2001 \mathrm{a})$ ). Certain XPs count as special derivational units, i.e., phases (see Chomsky (2001b, 2005a)). In this kind of approach, it is standardly assumed that all syntactic movement operations must be (a) local and (b) triggered by something (typically, certain features). As for (a), Chomsky (2000, 2001b) proposes a Phase Impenetrability Condition (PIC) that restricts search space in derivations; in its strictest form, the PIC states that a syntactic operation (like movement) can only see as far as the edge (i.e., specifier and head) domain of the previous phase, and not below this area. The PIC forces movement to apply successive-cyclically, via edge domains of phases that act as escape hatches. Crucially, Fox \& Pesetsky dispense with the PIC; there is no notion of escape hatch here. Rather, the necessity of successive-cyclic movement via phase edges is assumed to be derivable from cyclic linearization. As for (b), it is clear that if movement must take place via phase edges, and if all movement must be triggered, there must be a trigger (independent of locality considerations) that permits movement to phase edges. Here, one common suggestion is that optional EPP features can be inserted at phase edges if this "has an effect on outcome" (see Chomsky (2001b)). Fox \& Pesetsky simply presuppose that there is some such condition that permits intermediate movement steps to phase edges, i.e., successive-cyclic movement. Thus, whereas they are concerned with deriving the necessity of successive-cyclic movement (from cyclic linearization), they 
are not concerned with deriving the possibility of successive-cyclic movement.

The heart of their proposal can then be summarized as in (1).

(1) Cyclic linearization:

a. Linearization of syntactic structure applies cyclically, to spell-out domains (phases).

b. Spell-out domains are $\mathrm{CP}, \mathrm{VP} / \mathrm{vP}$, and DP.

c. Linearization adds new ordering statements to the set of statements established by the linearization of previous spell-out domains.

d. A new ordering statement generated in a spell-out domain must not contradict an ordering statement of a previous spell-out domain.

It follows from the system of cyclic linearization in (1) that shape conservation effects emerge as by-products: The linear ordering of items is regulated by external and internal Merge operations within a spell-out domain (and can repeatedly be changed within this domain), but it is fixed for the remainder of the derivation at the end of each spell-out domain. Essentially, spell-out domains (phases) act as stages of the derivation where a photograph is taken, and the information provided by this photograph is filed away and cannot be contradicted later in the derivation. Section 2.2 shows how this system of cyclic linearization derives the necessity of successive-cyclic movement.

\subsection{Successive-Cyclic Wh-Movement}

(2-a) illustrates a typical long-distance wh-dependency that crosses an embedded CP; and (2-b) exemplifies a highly local wh-movement operation. Under traditional assumptions (see Chomsky (1973)), (2-a) involves an intermediate movement step to the edge of the embedded clause (the CP phase). Given that $\mathrm{vP} / \mathrm{VP}$ is also a phase, there must also be intermediate movement steps to the edge of this domain in (2-a) and (2-b). ${ }^{3}$

(2) a. [CP What ${ }_{1}$ do you [vp $\mathrm{t}_{1}^{\prime \prime \prime}$ think [CP $\mathrm{t}_{1}^{\prime \prime}$ that she [vP $\mathrm{t}_{1}^{\prime}$ read $\left.\left.\left.\mathrm{t}_{1}\right]\right]\right]$ ?

b. [CP What ${ }_{1}$ did she $\left[\mathrm{vP} \mathrm{t}_{1}^{\prime}\right.$ read $\left.\left.\mathrm{t}_{1}\right]\right]$ ?

As noted above, it must be ensured that intermediate movement steps are both possible and necessary. One option for deriving the possibility is a condition like (3), here called Optional EPP Feature Condition (OFC), that controls the insertion of optional EPP features (see Chomsky (2000, 2001b).

\footnotetext{
${ }^{3}$ Fox and Pesetsky (2005a) tentatively assume that it is in fact VP that acts as a spell-out domain (phase) in a language like English; see below.
} 


\section{Gereon Müller}

\section{(3) Optional EPP Feature Condition (OFC):}

The head X of phase XP may be assigned an EPP-feature (after the phase $\mathrm{XP}$ is otherwise complete), but only if that has an effect on outcome.

It remains to be shown that the necessity of successive-cyclic movement via phase edges follows from cyclic linearization. Consider first a derivation in which $w h$-movement skips a phase edge on the way to its ultimate landing site, as in (4), which yields (2-b) without successive-cyclic movement.

(4) a. [vp read what $]$

b. [CP what ${ }_{1}$ did she [vp read $\left.\left.t_{1}\right]\right]$

$$
\begin{aligned}
& \rightarrow \text { read }<\text { what } \\
& \rightarrow * \text { what }<\text { read }
\end{aligned}
$$

There is no $w h$-movement to the edge of the spell-out domain VP in (4-a) (such movement is optional, given the OFC). Consequently, linearization of VP generates the ordering statement read $<$ what, which must not be contradicted in the remainder of the derivation. However, it is contradicted by (regular, feature-driven) $w h$-movement to the edge of CP in (4-b): Linearization of CP generates the ordering statement what $<$ read, and ungrammaticality arises due to conflicting ordering statements. The situation is different if $w h$-movement applies successive-cyclically, as in (5).

(5) a. [vP what read t $_{1}$ ]

b. [CP what ${ }_{1}$ did she $\left.\left[\mathrm{vP}^{\prime} \mathrm{t}_{1} \operatorname{read} \mathrm{t}_{1}\right]\right]$

$$
\rightarrow \text { what }<\text { read }
$$$$
\rightarrow \text { what }<\text { read }
$$

Here, movement to the edge of VP applies first; therefore, VP linearization generates the ordering statement what $<$ read. Subsequent movement and linearization in the CP domain generates the very same odering statement what $<$ read - if the $w h$-phrase precedes VP-internal material in the VP domain, it will also precede that material in the $\mathrm{CP}$ domain. More generally, it now follows that a $w h$-phrase originating in a non-edge position of VP can only end up in a SpecC position (where it precedes all other items of a clause) without contradicting the ordering statements for the spell-out domain VP if it first moves to the left-peripheral edge in VP. Thus, successive-cyclic movement is effected without recourse to a specific constraint like the PIC. ${ }^{4,5}$

\footnotetext{
${ }^{4}$ Note that it follows that items which are already left-peripheral in a given spell-out domain as a result of external Merge or regular, feature-driven (i.e., not OFC-triggerd) internal Merge do not have to move to a specific escape hatch. This issue can become relevant with, e.g., $w h$-objects and verbs in SOV languages (depending on whether vP or VP acts as a spellout domain).

${ }^{5}$ There are, however, certain PIC effects that cannot be derived from cyclic linearization. One example is the $w h$-island sensitivity of empty operator movement in, e.g., English relative clauses; see Heck (2005).
} 


\subsection{Simple Object Shift and Holmberg's Generalization}

A second welcome consequence of Fox \& Pesetsky's system of cyclic linearization is that shape conservation effects with object shift can be straightforwardly derived. Relevant generalizations that characterize the operation of (simple) object shift in the Scandinavian languages include the following (see Holmberg (1986, 1998), Vikner (1990, 1994), Collins and Thráinsson (1996)): Object shift moves DPs out of the VP, to a higher position that is TP-internal. The operation can affect (unstressed) pronominal DPs and nonpronominal DPs. In Icelandic, both types of DPs can undergo object shift; in the Mailand Scandinavian languages, only (unstressed) pronominal DPs can undergo object shift. The property of object shift that has arguably received most attention in the literature is its dependence on main verb raising to a position in front of the shifted object ('Holmberg's Generalization'). Pronominal object shift is obligatory (in contexts where it respects Holmberg's Generalization); non-pronominal object shift is optional throughout.

The obligatoriness of pronominal object shift in Danish is illustrated by the contrast between (6-a) and (6-b); the operation's dependence on main verb raising is exemplified by the examples in (6-cd), which involve a finite auxiliary and a non-finite main verb, and hence an absence of main verb raising in verb-second contexts. ${ }^{6}$

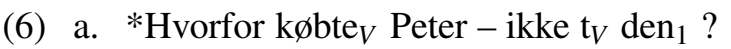

why bought Peter not it

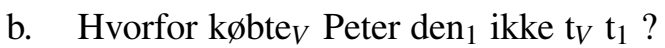

why bought Peter it not

c. Hvorfor skal Peter ikke købe den ${ }_{1}$ ?

why shall Peter not buy it

d. *Hvorfor skal Peter den ${ }_{1}$ ikke købe $t_{1}$ ? why shall Peter it not buy

Similarly, the examples in (7-ab) illustrate the obligatoriness of pronominal object shift in Swedish. ${ }^{7}$ The examples in (7-cd) and (7-ef) show that pronominal object shift in Swedish is impossible without raising of the main

\footnotetext{
${ }^{6}$ Mainland Scandinavian languages lack V-to-T movement but exhibit V-(to-T-)to-C movement in verb-second contexts; consequently, object shift can only take place in verbsecond contexts in these languages. The situation is different in Icelandic, which has standard (i.e., non-intermediate) V-to-T movement.

${ }^{7}$ Note, however, that there is some variation in judgements concerning the lack of pronominal object shift in main verb raising contexts.
} 


\section{Gereon Müller}

verb, in verb-second clauses where an auxiliary is the finite verb and in embedded clauses without verb-second, respectively.

(7) a. $(*) J a g$ kysste inte henne 1

I kissed not her

b. Jag kysste henne ${ }_{1}$ inte $t_{1}$

I kissed her not

c. Jag har inte kysst henne 1

I have not kissed her

d. *Jag har henne ${ }_{1}$ inte kysst $t_{1}$

I have her not kissed

e. att jag inte kysste henne ${ }_{1}$

that I not kissed her

f. *att jag henne ${ }_{1}$ inte kysste $\mathrm{t}_{1}$

that I her not kissed

The data in (8-ab) show that non-pronominal object shift in Icelandic is optional, and the data in $(8-\mathrm{cd})$ illustrate that this type of object shift requires main verb raising, too.

(8) a. Jón las ekki bækurnar

Jón read not the books

b. Jón las bækurnar ${ }_{1}$ ekki $\mathrm{t}_{1}$

Jón read the books not

c. Jón hefur ekki lesið bækurnar ${ }_{1}$

Jón has not read the books

d. *Jón hefur bækurnar ${ }_{1}$ ekki lesið $\mathrm{t}_{1}$

Jón has the books not read

Following earlier work by Williams (2003), Fox and Pesetsky (2005a) assume that Holmberg's Generalization should be viewed as a shape conservation effect with object shift. Two assumptions prove crucial: First, the landing site of object shift is outside the spell-out domain (phase) VP (but below TP). Second, object shift cannot target a phase-edge position as an intermediate landing site (in contrast to $w h$-movement). It is this second assumption in particular that is indispensible if the shape conservation effect with object shift is to be derived from cyclic linearization. ${ }^{8}$ On this basis, Holmberg's

${ }^{8}$ There are various ways to motivate this assumption. One possibility would be to invoke the fact that object shift has A-movement properties (see Vikner (1994)); if a phase-edge position qualifies as an A-bar position, an intermediate movement step to the edge of the 
Generalization follows without further ado. Linearization of VP invariably generates an ordering statement $\mathrm{V}<\mathrm{DP}$ (optional intermediate movement to the phase edge is not available with object shift). This ordering statement remains present througout the rest of the derivation; and it must not be contradicted by another ordering statement that is generated later. However, if object shift out of VP takes place and is not accompanied by further raising of the main verb, subsequent linearization of $\mathrm{CP}$ generates a contradictory ordering statement $\mathrm{DP}<\mathrm{V}$, and ungrammaticality results. If, on the other hand, object shift is accompanied by further raising of the main verb to a higher position, subsequent linearization of $\mathrm{CP}$ generates an ordering statement $\mathrm{V}$ $<$ DP that is identical to the statement generated earlier; so the movement operation is licit. Thus, Holmberg's Generalization is derived as a shape conservation effect that follows automatically from general assumptions about cyclic linearization.

\subsection{Multiple Object Shift}

There is a similar shape conservation effect with multiple object shift of pronouns and non-pronominal DPs in double object constructions (see Vikner (1990), Johnson (1991), and Collins and Thráinsson (1996), among others). In Scandinavian double object constructions, the order is indirect object before direct object. This order must be strictly respected by multiple object shift of two pronouns in Danish; cf. (9).

(9) a. Peter viste hende den $_{2}$ jo $t_{1} t_{2}$ Peter showed her it indeed

b. *Peter viste den hende $_{1}$ jo $\mathrm{t}_{1} \mathrm{t}_{2}$

c. *Peter viste -- jo hende ${ }_{1}$ den $_{2}$

d. *Peter viste -- jo den hende $_{1}$

e. *Peter viste hende $1-$ jo $_{1}$ den $_{2}$

f. *Peter viste - den $_{2}$ jo hende 1

If only one of the two objects is a pronoun, it must be the indirect object; object shift of a direct object pronoun across a non-pronominal indirect object fails to preserve the VP-internal order and is blocked; see (10).

(10) a. *Peter viste den 2 jo Marie $_{1} \mathrm{t}_{2}$ Peter showed it indeed Marie

spell-out domain in the course of object shift might induce an improper movement effect (reducible to Principle C of the binding theory, as in Chomsky (1981), or to the Principle of Unambiguous Binding in Müller and Sternefeld (1993)). 
b. Peter viste hende ${ }_{1}$ jo $t_{1}$ bogen $_{2}$
Peter showed her indeed the book

Essentially the same situation obtains with multiple optional object shift of non-pronominal DPs in Icelandic. The examples in (11) show that multiple object shift must preserve the VP-internal order; and the examples in (12) show that if only one of the two objects undergoes object shift, it must be the indirect object, so that the pre-movement order is maintained after the operation.

(11) a. Ég lána Maríu bækurnar $_{2}$ ekki $\mathrm{t}_{1} \mathrm{t}_{2}$

I lend Maria the books not

b. *Ég lána bækurnar 2 Maríu $_{1}$ ekki $\mathrm{t}_{1} \mathrm{t}_{2}$

I lend the books Maria not

(12) a. *Ég lána bækurnar 2 ekki Maríu $\mathrm{t}_{2}$

I lend the books not Maria

b. Ég lána Maríu ekki $_{1}$ bækurnar $_{2}$

I lend Maria not the books

The account that can be given in Fox \& Pesetsky's framework is exactly as before: Linearization of $\mathrm{VP}$ generates the three ordering statements $\mathrm{V}<\mathrm{DP}_{I O}$, $\mathrm{V}<\mathrm{DP}_{D O}$, and $\mathrm{DP}_{I O}<\mathrm{DP}_{D O}$. These ordering statements can only be respected after (multiple) object shift if (a) the main $\mathrm{V}$ moves to a higher position in front of both objects, and (b) the two shifted objects reassemble in their pre-movement order: $\mathrm{V}<\mathrm{DP}_{I O}, \mathrm{~V}<\mathrm{DP}_{D O}$, and $\mathrm{DP}_{I O}<\mathrm{DP}_{D O}$. A derivation in which the main verb fails to move contradicts an ordering statement in the VP domain, as with simple object shift (Holmberg's Generalization): $\mathrm{DP}_{I O}<\mathrm{V}, \mathrm{DP}_{D O}<\mathrm{V}$. However, for the same reasons, a derivation in which the two shifted objects fail to preserve the pre-movement order established in VP is also ruled out: $\mathrm{DP}_{D O}<\mathrm{DP}_{I O}$ contradicts the earlier linearization statement $\mathrm{DP}_{I O}<\mathrm{DP}_{D O}$.

To sum up so far, Fox \& Pesetsky's set of simple assumptions about cyclic linearization succeeds in deriving the necessity of intermediate movement steps to phase edges with $w h$-movement (more generally, A-bar movement) without invoking a special constraint like the PIC, and it accounts for the shape-preserving nature of object shift without invoking a special requirement demanding just that (like the Shape Conservation constraints in Williams (2003), Müller (2000)), given that the former movement type can target phase edges as intermediate landing sites, and the latter one cannot. Still, Fox \& Pesetsky's approach also raises a number of questions. 


\section{Problems}

\subsection{Spell-Out Domains}

A first potential problem is related to the notion of spell-out domain. As noted in footnote 3, Fox and Pesetsky (2005a) assume that it is VP rather than vP that acts as a spell-out domain in English and Scandinavian; thus, this spellout domain does not correspond to the notion of phase in Chomsky (2000, 2001b). As things stand, this assumption is unavoidable. To see this, suppose that $\mathrm{vP}$ is the spell-out domain (and VP is not). Then, an ordering statement $\mathrm{DP}_{S}<\mathrm{V}$ established in $\mathrm{vP}$ (with the external argument DP merged in Specv) would invariably be contradicted by a possible later ordering statement $\mathrm{V}<$ $\mathrm{DP}_{S}$ after verb-second movement to C. This problem is illustrated for verbsecond movement wh-questions in Danish in (13). The external argument precedes the finite verb in vP in (13-a), and follows the finite verb in (13-b). However, the first linearization statement is not generated if VP rather than vP is the relevant spell-out domain (the external argument has not yet been merged when VP linearization takes place).

(13) a. [vp Peter købte den ]

Peter bought it

b. [СР Hvorfor købte ${ }_{0}\left[\right.$ TеP Peter $_{2} \mathrm{t}_{0}^{\prime}$ den $_{1}$ ikke [vP $\left.\left.\left.\mathrm{t}_{2} \mathrm{t}_{0} \mathrm{t}_{1}\right]\right]\right]$ ?

why bought Peter it not

Thus, the assumption that VP rather than vP is the spell-out domain in Danish seems crucial. ${ }^{9}$ This may be incompatible with the idea that phases are semantically motivated as propositional units (see Chomsky $(2000,106)$ ), which then includes the base position of the external argument. It follows that if VP is a spell-out domain, either spell-out domains do not have to equal phases, or phases are not semantically motivated in the way Chomsky suggests. Furthermore, there is independent phonological motivation for vPs as phases (see Legate (2003), Ishihara (2004), Richards (2004), Kratzer and Selkirk (2007))). Finally, Fox and Pesetsky (2005a) (based on Ko (2004)) suggest that there may be a parametrization with respect to vP or VP as the relevant spell-out domain (with Korean choosing the former option, English and Scandinavian the latter one); again, this may possibly be considered problematic from a conceptual point of view if one assumes a semantic grounding of phases.

\footnotetext{
${ }^{9}$ See, however, Fox and Pesetsky (2003) for a more elaborate approach that relies on a set of further assumptions (concerning overt vs. covert movement) under which this consequence does not hold.
} 
More importantly, there are empirical problems with the assumption that VP (and not vP) is the relevant spell-out domain. The evidence comes from shape conservation phenomena with multiple pronominal object shift in German and multiple wh-movement in Bulgarian. In both cases, there is good reason to assume (based on Fox \& Pesetsky's general assumptions) that an ordering statement must be generated for an external argument in Specv and an object in the complement position of $\mathrm{V}$. I begin with pronoun fronting in German.

\subsubsection{Pronoun Fronting in German}

The following generalizations describe the basic behaviour of unstressed personal pronouns in German (see, among others, Bierwisch (1963, 99-101), Lenerz (1977), and Heidolph et al. (1981)). Unstressed pronouns are obligatorily moved across adverbs and non-pronominal DPs; see (14-ab) vs. (14-c). There is only one kind of element that may precede unstressed pronouns and follow C (i.e., remain TP-internal), and that is an external argument bearing nominative case (i.e., a subject); cf. (14-de). This follows if scrambling targets a lower position than pronoun fronting, and if only external arguments bearing nominative case may undergo movement to the subject position SpecT; this latter movement is always optional.

(14) a. *dass gestern der Fritz es 1 gelesen hat that yesterday the Fritz it read has

b. *dass gestern es ${ }_{1}$ der Fritz $\mathrm{t}_{1}$ gelesen hat that yesterday it the Fritz read has

c. dass es 1 gestern der Fritz $\mathrm{t}_{1}$ gelesen hat that it yesterday the Fritz read has

d. dass der Fritz es ${ }_{1}$ gestern $t_{1}$ gelesen hat that the Fritz it yesterday read has

e. *dass der Fritz gestern es 1 gelesen hat that the Fritz yesterday it read has

If more than one DP argument in a clause is an unstressed pronoun, pronoun fronting applies multiply. As with Scandinavian object shift, there are shape conservation effects (see Müller (2001)). These effects occur, e.g., when the two unstressed pronouns are subject and object: The pre-movement order $\mathrm{DP}_{S}<\mathrm{DP}_{O}$ must strictly be adhered to after multiple pronoun fronting. This is illustrated by the sentence pair in (15). 
(15) a. dass $\operatorname{sie}_{1} \quad$ es$_{2}$ gestern $t_{1} t_{2}$ gelesen hat

that she $_{\text {nom }} \mathrm{it}_{\text {acc }}$ yesterday read has

b. *dass es sie $_{1}$ gestern $t_{1} t_{2}$ gelesen hat

that it $_{a c c}$ she $_{\text {nom }}$ yesterday read has

The strict $\mathrm{DP}_{S}<\mathrm{DP}_{O}$ order after pronoun fronting of subject and object cannot be due to obligatory subject raising (as it may be in comparable cases in the Scandinavian languages) because, as we have just seen (cf. (14-c)), German does not have obligatory raising to subject position. However, the phenomenon can straightforwardly be derived from cyclic linearization but only if an external argument merged in Specv and an internal argument merged with $\mathrm{V}$ have a common spell-out domain. The relevant domain must then be vP. Of course, this reasoning raises immediate questions within Fox $\&$ Pesetsky's framework. Most notably, how can an object pronoun move across a subject DP in Specv in the first place? Assuming Specv to be available as an intermediate landing site for German pronoun fronting cannot be the solution because we would then not expect any shape conservation effect with pronoun fronting. So we face a dilemma: The shape conservation effect in (15-b) strongly suggests cyclic linearization at work; but then, it becomes unclear how sentences like (14-c) can be permitted. Furthermore, since German has verb-second clauses in which a finite main verb in $\mathrm{C}$ precedes a subject (in SpecT or in Specv), assuming vP to be a spell-out domain in German creates the very same problem that it does in Scandinavian languages like Danish (see (13)).

In what follows, I will assume that the shape conservation effects with Scandinavian object shift and German pronoun fronting can and should be derived in essentially the same way (but note that this does not imply that the two operations are identical).

\subsubsection{Wh-Movement in Bulgarian}

Wh-movement in Bulgarian exhibits the following properties (cf., among others, Rudin (1988), Billings and Rudin (1996), Grewendorf (2001), Richards (2001), and Bošković (2002b)): All wh-phrases are fronted to the C domain in multiple questions. An (agentive) wh-subject (which we may take to be the prototypical external argument merged in Specv) and a wh-object exhibit strict shape conservation; they always show up in the order $\mathrm{DP}_{S}<\mathrm{DP}_{O}$. The situation is somewhat more involved with two objects (an indirect object $\mathrm{DP}_{I O}$ and a direct object $\left.\mathrm{DP}_{D O}\right)$. Here, the order is often $\mathrm{DP}_{I O}<\mathrm{DP}_{D O}$, but there are intervening factors (related to, e.g., animacy and categorial sta- 
tus (DP vs. PP)), and there is often optionality. Here and henceforth, I will assume that the variation in linear order in the $\mathrm{C}$ domain observed with multiple wh-movement applying to two objects can be traced back to variation that exists already within VP. ${ }^{10}$ The generalization that is more interesting in the present context concerns the fixed linear order of subject and object wh-phrase in the $\mathrm{C}$ domain; compare, e.g., (16):
(16) a. [CP $\mathrm{Koj}_{1} \quad \operatorname{kogo}_{2} \quad \mathrm{C}\left[\mathrm{vp}_{1} \mathrm{t}_{1}\right.$ vižda $\left.\left.\mathrm{t}_{2}\right]\right]$ ? who $_{\text {nom }}$ whom $_{\text {acc }}$ sees
b. *[CP $\mathrm{KogO}_{2} \quad \mathrm{koj}_{1} \quad \mathrm{C}\left[\mathrm{vp}_{1} \mathrm{t}_{1}\right.$ vižda $\left.\left.\mathrm{t}_{2}\right]\right]$ ? whom ${ }_{\text {acc }}$ who $_{\text {nom }}$ sees

As before, on the basis of Fox \& Pesetsky's general assumptions, the clear shape conservation effect that can be observed here suggests that subjects and objects are part of one linearization domain, which then implies that $\mathrm{vP}$ is indeed a spell-out domain (note that this holds independently of whether or not there is raising to SpecT). And again, this assumption is incompatible with V-to-C movement in front of subject DPs - an operation that is available in Bulgarian as it is in Danish or German.

\subsection{A-Movement in Passive Constructions}

A second problem arises under the assumption that unaccusative, passive and raising vPs (or VPs - the difference is immaterial in the present context) are phases (spell-out domains); this assumption has recently been argued for from different empirical and theoretical perspectives (see, e.g., Legate (2003) and Richards (2004)). If unaccusative and passive vPs are spell-out domains, Fox and Pesetsky's analysis makes wrong predictions: An ordering statement $\mathrm{V}<\mathrm{DP}_{O}$ in the $\mathrm{vP} / \mathrm{VP}$ domain is later followed by a reverse ordering statement $\mathrm{DP}_{O}<\mathrm{V}$ in the $\mathrm{CP}$ domain, and we should thus wrongly expect subject movement to SpecT in passive or raising constructions to lead to ungrammaticality (assuming that standard A-movement, like object shift, cannot proceed successive-cyclically, via the edge of the spell-out domain). Consider the derivations in (17-a) (passive) and (17-b) (raising) in English (with (i) the lower spell-out domain, and (ii) the higher, final spell-out domain).

(17) a. (i) [vp hit-v [vP t John 1 ]]

(ii) [ $\mathrm{CP} C\left[\mathrm{TP} \mathrm{John}_{1}\right.$ was $\left[\mathrm{vP}\right.$ hit-v $\left.\left[\mathrm{t} \mathrm{t}_{1}\right]\right]$

b. (i) [ $\mathrm{vP} v$ [vP seems [ $\mathrm{TP}^{\mathrm{V}}$ Mary 1 to be smart ]]

\footnotetext{
${ }^{10}$ This assumption may not be entirely uncontroversial, but it is not crucial here either.
} 
(ii) [СР C [те Mary 1 T [vP seems-v [ ${ }_{\mathrm{TP}} \mathrm{t}_{1}$ to be smart ]]]]

As observed by Bobaljik $(2005,121)$, the same phenomenon shows up with A-movement in passivized double object constructions in Icelandic; but here the problem might be even more pressing because in addition to a violation of shape conservation with $\mathrm{DP}_{1}$ in SpecT and the verb, there is what might be interpreted as a shape conservation effect among the two DPs (only DP 1 can move to SpecT; $\mathrm{DP}_{2}$ cannot undergo such movement). ${ }^{11}$ Consider the derivation in (18), with the vP/VP spell-out domain in (18-a), and the CP spell-out domain in (18-b) (data from Zaenen et al. (1985)).

(18) a. [vP v [vP gefnar konunginum ${ }_{1}$ ambáttir $\left.\left._{2}\right]\right]$

$$
\text { given the king } \text { dat }_{\text {slaves }} \text { nom }
$$

b. [CP Um veturinn voru [TP konunginum ${ }_{1}{ }_{\mathrm{vP}}$ gefnar-v [ $\mathrm{vP}_{\mathrm{vP}} \mathrm{t}_{1}$ in the winter were ${ }_{p l}$ the king $_{d a t}$ given ambáttir $\left.\left.\left.{ }_{2}\right]\right]\right]$

slaves $_{\text {nom }}$

\subsection{Verb-Second in SOV languages}

So far, we have seen that the existence of verb-second constructions in SVO languages necessitates the assumption that VP rather than $\mathrm{vP}$ is the spell-out domain (so that an external argument in Specv can end up in a position that follows a verb that has undergone movement to $\mathrm{C}$ ); and we have also seen that the same consequence holds for SOV languages. Now I will argue that the problem posed by verb-second constructions in SOV languages is in fact much more general than that, and cannot be solved by making assumptions concerning the parametrization of spell-out domains (vP vs. VP).

Verb-second in an SOV language like German may systematically reverse the ordering statements of the lower spell-out domain. The two examples in (19-ab) show this for subjects merged in $\mathrm{vP} ; \mathrm{V}$ follows $\mathrm{DP}_{1}$ in the lower spell-out domain vP (embedded clauses have verb-final order), and $\mathrm{V}$ precedes $\mathrm{DP}_{1}$ on the $\mathrm{CP}$ cycle. This case can in principle be handled in Fox and Pesetsky's system if we assume that VP is the relevant spell-out domain (but recall that there is evidence from pronoun fronting which indicates that subjects do belong to the lower spell-out domain).

\footnotetext{
${ }^{11}$ However, this may alternatively be accounted for as a minimality effect, derivable from a constraint like the Minimal Link Condition.
} 

(19) a. Gestern arbeitete $_{0}\left[\mathrm{vP}\right.$ Maria $_{1} \quad$ [vp zu Hause to t $\left._{0}\right]$ yesterday worked Maria nom $_{\text {at }}$ at home
b. dass [vp Maria ${ }_{1}$ [vp zu Hause arbeitete $\left.{ }_{0}\right]$ that Maria $_{\text {nom }}$ at home worked

However, the verb-second construction in (20-a) cannot be accounted for by parametrizing spell-out domains: As evidenced by the analogous construction without verb-second in (20-b), $\mathrm{V}$ follows $\mathrm{DP}_{2}$ in the lower spell-out domain (be it vP or VP) in (20-a) but precedes $\mathrm{DP}_{2}$ in the higher spell-out domain $(\mathrm{CP})$. Thus, the only kind of verb-second clause that could be derived on the basis of the VP in (20-b) in accordance with Fox and Pesetsky's assumptions (given that $\mathrm{vP}$ is not a spell-out domain) would be (20-c), with a topicalized object.

$$
\begin{aligned}
& \text { (20) a. Maria } \left.1 \text { laso [vP } \mathrm{t}_{1}\left[\mathrm{vp} \text { das } \mathrm{Buch}_{2} \mathrm{t}_{0}\right]\right] \\
& \text { Maria }_{\text {nom }} \text { read the book }{ }_{a c c} \\
& \text { b. dass [vP Maria }{ }_{1} \text { [vp das } \text { Buch }_{2} \text { las } 0 \text { ]] } \\
& \text { that Maria }{ }_{\text {nom }} \text { a } \text { book }_{\text {acc }} \text { read } \\
& \text { c. Das Buch } \text { las }_{0}\left[\mathrm{vp}^{\mathrm{Maria}}{ }_{1} \quad\left[\mathrm{vp}_{2} \mathrm{t}_{0}\right]\right] \\
& \text { the } \text { book }_{a c c} \text { read Maria }{ }_{n o m}
\end{aligned}
$$

To conclude, the order reversal involving a finite verb and an object that takes place between the verb-final VP (or vP) domain and the verb-second CP domain poses a problem for Fox and Pesetsky's analysis. ${ }^{12}$ Possible solutions would then minimally seem to require non-trivial and somewhat unusual assumptions about verb placement in SOV languages with verb-second.

Here is a first attempt at a solution. Suppose that SOV languages have a uniform base order where the verb precedes the object $(\mathrm{V}<\mathrm{DP})$, as contemplated in the last footnote. Suppose next that an object DP moves across the verb before the spell-out domain is reached in verb-final clauses (as in (20-b)); and that the object DP fails to undergo such movement to a linearization-domain internal pre-verbal position in verb second clauses (as in (20-a)) - unless, that is, the object DP eventually ends up in front of the verb in topic position, as in (20-c), in which case it has to undergo local movement across the verb. Such an approach might work, but it would arguably be somewhat

\footnotetext{
${ }^{12}$ Note that this problem persists under an antisymmetric approach according to which OV predicate phrases are derived from a basic VO structure (see Kayne (1994)), as long as we make the assumption that the derived OV structure then feeds further derivational steps on, e.g., the TP and CP cycles (cf. Zwart (1993)). However, things are different if this latter assumption is not made; see Hallman (2000) and the following remarks in the main text.
} 
ad hoc; and it is far from clear how verb movement to $\mathrm{C}$ could block local object movement (as a kind of Anti-Holmberg's Generalization effect) in most contexts and force local object movement in contexts where the object is eventually topicalized.

Let me therefore consider a second solution, one that does not rely on local object movement across the verb, but rather on local verb movement across the object. Suppose, as before, that SOV languages have a uniform base order; however, this time the uniform order is DP $<\mathrm{V}$. In verb-second clauses like (20-c), the verb raises to a position in front of the DP before the spell-out domain is reached, so there is a V > DP linearization on the vP/VP cycle that subsequent verb-second movement adheres to. On the other hand, the verb stays in situ in verb-final clauses like (20-b). For object-initial verbsecond clauses like (20-c), it can then be assumed that the object must move to a phase-edge position first if it is to undergo movement to SpecC later, and since it thus precedes a locally moved verb before spell-out of the lower linearization domain takes place, the pattern vivsible in (20) is derived.

Still, this kind of approach is not completely unproblematic either. The main problem I see is this: The apparent instance of order reversal that is visible in (20) can only be accounted for if an extremely abstract base structure of the vPs in question is assumed. However, this assumption threatens to undermine the whole approach: If highly abstract linearization domains (that are never attested on the surface) are available for the SOV language German, one might wonder why they are not available for the Scandinavian SVO languages - in the latter, a surface-oriented approach seems crucial. For these reasons, then, verb-second in SOV languages continues to pose a problem in Fox and Pesetsky's approach. ${ }^{13}$

\subsection{Intermediate Landing Sites}

The crucial difference between movement types that respect (a pre-theoretic concept of) shape conservation (e.g., Scandinavian object shift) and movement types that do not (e.g., English $w h$-movement) boils down to the ability or inability to move successive-cyclically via SpecC. This fact has sometimes

\footnotetext{
${ }^{13}$ It should be noted that the issue of verb-second in SOV languages is eventually addressed at the very end of the extended handout that is Fox and Pesetsky (2003) (viz., on p. 44). Fox and Pesetsky suggest that "covert merge of V and object" is involved. Notwithstanding other problems with the concept of covert operations under Fox and Pesetsky's general set of assumptions (concerning the interaction of quantifier raising and deletion; see Heck (2005)), this can be taken as evidence that verb-second in SOV languages is a priori unexpected, and requires extra assumptions, in their system of cyclic linearization.
} 
been regarded as a problem because an important building block of the overall approach in Fox and Pesetsky (2005a) has thus been left unspecified (see Nilsen (2005), Williams (2005), Bobaljik (2005), and Müller (2005)). Fox and Pesetsky (2005a) are well aware of this; they note that "our proposals say nothing in themselves [...] about the circumstances under which movement to these left-edge positions is allowed or prohibited." As noted above (see footnote 8), the availability of an intermediate phase-edge position for whmovement, and the unavailability of such a position for Scandinavian object shift, may well follow from the theory of improper movement, given an A/Abar distinction among movement types. Now, such an approach is not entirely unproblematic. For instance, it fails to account for shape conservation effects with pronoun fronting in German (which shows A-bar properties like parasitic gap licensing; see Vikner (1994) and below). It also does not provide an immediate account of the fact that A-movement in passive contexts can to some extent violate shape conservation (viz., with respect to the verb). However, it seems to me that these problems of classifying the circumstances under which a movement operation may target an intermediate phase-edge position are to some extent orthogonal to Fox and Pesetsky's main claims, and may in principle be solved within their approach.

Still, I would like to contend that there is a much more general conceptual problem lurking here. As has been noted by Sells (2001) and Richards (2004), it does not seem accidental that the shape conservation property of object shift (with respect to $\mathrm{V}$ ) is correlated with the fact that this operation is extremely local, and that the failure of, say, $w h$-movement to obey shape conservation (with respect to $\mathrm{V}$ ) is correlated with the fact that this operation is inherently non-local (and can apply long-distance). In fact, even A-movement to SpecT is less local than object shift, and, as noted above, it does not obey shape conservation with respect to $\mathrm{V}$. Thus, the correct generalization underlying shape conservation effects with respect to $\mathrm{V}$ does not involve a concept like the A-bar vs. A distinction; rather, the correct generalization seems to be that only extremely local operations (i.e., operations whose final landing site is very close to the base position) obey shape conservation with respect to $\mathrm{V}$. This generalization cannot be captured in Fox and Pesetsky's approach in a natural way.

\subsection{Derivational Syntax}

Finally, I would like to point out a potential conceptual peculiarity. Fox and Pesetsky (2005a) assume a derivational organization of syntax. However, 
closer inspection reveals that there is in fact a large representational residue (also see Sells (2005)). First, note that all ordering statements that have been generated for a given spell-out domain remain active and visible throughout the rest of the derivation. Arguably, in a strictly derivational approach, information that has undergone cyclic spell-out should become inaccessible, and irrelevant, at subsequent stages of the derivation (see, e.g., Epstein and Seely (2002)). Second, recall that the Phase Impenetrability Condition (PIC) is abandoned in Fox and Pesetsky's (2005a) approach. The PIC derives locality constraints on movement; however, it is motivated in Chomsky $(2000,2001 b)$ primarily by complexity considerations (viz., reduction of search space) rather than empirically, as a locality constraint. The latter task is accomplished by cyclic linearization in the present approach; but the former task is not: Search space is in principle unlimited here. Thus, it is not so clear that dispensing with the PIC is a virtue, assuming that the PIC's main task is that of reducing search space.

To conclude this section, I have argued that there are a number of empirical and conceptual problems with Fox and Pesetsky's system of cyclic linearization. On the empirical side, the approach turns out to be both too strong (e.g., it rules out non-object initial verb-second in SOV languages, and A-movement in passive contexts on the assumption that a local spellout domain is involved here), and too weak (e.g., it does not derive shape conservation effects with pronoun fronting in German and wh-movement in Bulgarian). On the conceptual side, the approach relies on a parametrization of spell-out domains (VP vs. vP) that may be regarded as conceptually suboptimal (and also empirically problematic, as argued for pronoun fronting in German). Furthermore, it does not capture the generalization that only extremely local movement types exhibit shape conservation effects with respect to V. Finally, by providing syntactic access to the complete representation built up so far at every step of the derivation, there is a theoretical heterogeneity that may be regarded as conceptually unattractive. In view of this, I will attempt to revise Fox and Pesetsky's (2005a) approach to shape conservation effects in terms of cyclic linearization. ${ }^{14}$

The revised approach to cyclic linearization as a source of shape conservation effects to be developed in what follows relies on three main assump-

\footnotetext{
${ }^{14}$ I hasten to add that the empirical covergage will not be identical. For instance, it follows without further assumptions in Fox \& Pesetsky's approach that preposing of negative quantifiers is incompatible with verb movement to a higher position in Icelandic (an AntiHolmberg's Generalization effect); the present approach will have nothing to say about this restriction.
} 
tions. The first assumption is that syntax exhibits a strictly derivational organization. This implies that pieces of information that are accessible at one stage of the derivation (including ordering statements) may be inaccessible at later stages; i.e., information may be lost in the course of the derivation. Second, the approach is based on a relativization of ordering statements: Instead of fixed spell-out domains (like vP/VP and CP), the creation of ordering statements is assumed to be a relativized property of two structure-building operations - feature-driven vs. non-feature-driven Merge. ${ }^{15}$ Third and finally, a theory of successive-cyclic movement is presupposed which captures the difference between movement that reaches its target position and movement that does not, and which has the effect of forcing all movement to apply successive-cyclically, in steps that are highly local. Since the theory of successive-cyclicity is a prerequisite for the derivational, relativized approach to cyclic linearization, it is addressed first, in the following section.

\section{Successive-Cyclic Movement}

I assume the (stricter version of the) Phrase Impenetrability Condition introduced in Chomsky (2000, 108; 2001, 13); see (21).

\section{(21) Phase Impenetrability Condition (PIC):}

The domain of a head X of a phase XP is not accessible to operations outside XP; only X and its edge are accessible to such operations.

The PIC requires successive-cyclic movement to take place via phase edges. Given that unforced movement is blocked (cf. the Last Resort requirement on syntactic operations), there must be another constraint that forces movement to an intermediate position. One candidate for this constraint is what I have called the "Optional EPP Feature Condition" (OFC; see Chomsky (2000, 2001b) - recall that, according to the OFC, the head X of phase XP may be assigned an EPP-feature, subject to the requirement that this has then an effect on outcome). Another possibility is the constraint Phase Balance that has first been introduced in Heck and Müller (2000) (also see Müller (2004), Fischer (2004), Heck (2004), and Heck and Müller (2006a)). It is an approach based on this latter constraint that I will adopt here. ${ }^{16}$ Phase

\footnotetext{
${ }^{15}$ Also see Fanselow and Lenertová (2007) for a related assumption (viz., that XPs with an operator feature are not serialized immediately).

${ }^{16}$ One should bear in mind, however, that the alternative approach could in principle also be adopted, as long as it is ensured that the system can distinguish between regular featuredriven movement, and movement triggered by optional EPP-features. The main reason for
} 
Balance can be defined as in (22).

(22) Phase Balance:

Every phase has to be balanced: For every feature $[\bullet \mathrm{F} \bullet]$ in the numeration there must be a potentially available feature $[\mathrm{F}]$ at the phase level.

Phase Balance presupposes a distinction between two kinds of features relevant for movement: $[\bullet \mathrm{F} \bullet$ is a probe feature with an EPP (or, more generally, movement-inducing) property, and $[\mathrm{F}]$ is a matching goal feature. ${ }^{17}$ To find out whether a phase is balanced, the derivation looks into the numeration and scans the $[\bullet \mathrm{F} \bullet]$ features still located there. For each of these $[\bullet \mathrm{F} \bullet]$ features, there must be a corresponding $[\mathrm{F}]$ that is potentially available. There are two ways how an $[\mathrm{F}]$ feature can be potentially available for a matching $[\bullet \mathrm{F} \bullet]$ feature. The straightforward one is that $[\mathrm{F}]$ is present either in the numeration, or in a tree that has been constructed outside of the present derivation by a separate derivation, and is waiting to be merged with the present tree at some later point; these domains can be referred to as the workspace of the present derivation. However, there is a possibility that no matching $[\mathrm{F}]$ feature is present in the workspace because the item bearing $[\mathrm{F}]$ has already been

adopting the Phase Balance-based approach here is that it is fully explicit about the circumstances under which intermediate movement is triggered, and does not resort to a vague requirement like "having an effect on output". That said, the present approach can to some extent be viewed as a formal elaboration of what it means to "have an effect on output." From this perspective, the only fundamental difference between these two approaches concerns the presence or absence of features as triggers for intermediate movement steps. However, this difference is not crucial either. Phase Balance, which will momentarily be shown to act as a trigger for non-feature-driven movement, could in principle also be viewed as a trigger for the insertion of features (which in turn force movement), in which case the OFC-based approach and the Phase Balance-based approach might eventually emerge as closely related variants of the same concept. See Heck and Müller (2006b); and Biskup (2005) for a related proposal based on feature insertion. A feature-based version of the Phase Balance approach to successive-cyclic movement will nevertheless not be pursued here, mainly because it adds unnecessary complexity to the system. (McCloskey (2002) argues that a feature-based approach is better equipped to handle morphological reflexes of successive-cyclicity, but we argue in Heck and Müller (2006a) that this is not the case under current approaches to morphological spell-out (like distributed morphology).)

${ }^{17}$ See Frampton and Gutman (1999), Gärtner (2002), Adger (2003), Roberts and Roussou (2002), Sternefeld (2006), and Heck and Müller (2006b) for feature systems involving this kind of diacritic (with similar, but not necessarily identical interpretations). In earlier work (cf., e.g., Heck and Müller (2000, 2006a)), we rendered probe features that are accompanied by an EPP property as $\left[{ }^{*} \mathrm{~F}^{*}\right]$ rather than $[\bullet \mathrm{F} \bullet]$; however, we will now reserve the $\left[{ }^{*} \mathrm{~F}^{*}\right]$ notation for cases of 'pure' probe features that trigger Agree and lack an EPP property; see Heck and Müller (2006b). 
merged in the present derivation. ${ }^{18}$ Then, it can only be potentially available for $[\bullet \mathrm{F} \bullet]$ in the numeration if it is part of the edge domain of the current phase; and (with the exception of underived phase specifiers; but see below) the only way to ensure the presence of $[\mathrm{F}]$ in the edge domain of a phase is by movement of the category bearing $[\mathrm{F}]$. This will then derive intermediate steps of successive-cyclic movement, in (minimal) violation of the Last Resort constraint that blocks non-feature-driven movement. The notion of potential availability can thus be defined as in (23).

(23) Potential availability:

A feature $[\mathrm{F}]$ is potentially available if (i) or (ii) holds:

(i) $[\mathrm{F}]$ is on $\mathrm{X}$ or edgeX of the present root of the derivation.

(ii) $[\mathrm{F}]$ is in the workspace of the derivation.

As an abstract example of how the system works, consider a stage of a deriva-

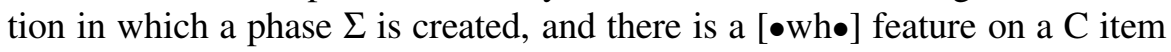
that is still part of the numeration. $\Sigma$ must be balanced, so there must be a

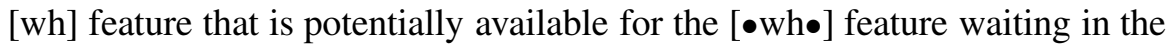
numeration. Suppose now first that there is a [wh] feature on some other item in the numeration (say, a bare $w h$-phrase like $w h o$ ), or on some other item outside the numeration but within the workspace (say, a complex $w h$-phrase like which woman, which may have been formed already). Then, Phase Balance does not trigger any movement to the specifier of $\Sigma$, regardless of whether there is a [wh] feature within $\Sigma$ or not. ${ }^{19}$ In contrast, suppose now that there is in fact no $[\mathrm{wh}]$ feature for the $[\bullet \mathrm{wh} \bullet]$ probe in the workspace; then, a phaseinternal $w h$-phrase bearing [wh] must move to the specifier of the phase in order to respect Phase Balance, even if this violates the Last Resort requirement because there is no feature that might trigger the operation. This way, successive-cyclic movement from phase to phase is brought about.

Next, the question arises of what constitutes a phase. I assume that all saturated XPs qualify as phases. Thus, all XPs are phases, except for VP,

\footnotetext{
${ }^{18}$ In principle, it might also be possible that $[\mathrm{F}]$ is neither part of the workspace, nor of the current derivation. In that case, the derivation will crash. Arguably, such an option is unwanted from the perspective of crash-proof syntax. It can be excluded in a simple and principled way by imposing a count invariant requirement (as it is known from categorial grammar), such that the number of $[\bullet \mathrm{F} \bullet] \mathrm{s}$ must equal the number of $[\mathrm{F}] \mathrm{s}$ in the numeration; see van Benthem (1988), Stabler (1996) on count invariants.

${ }^{19}$ As shown in Müller (2004) and Heck and Müller (2006a), this derives various types of superiority and superiority-like effects, without recourse to a constraint like the MLC - a $w h$-phrase cannot move to the specifier of a phase if there is another [wh] feature on some item outside the present derivation.
} 
which counts as part of the vP phase. ${ }^{20} \mathrm{VP}$ is special in being systematically accompanied by an additional projection vP, and it is unique among XPs in realizing certain types of arguments of its head (viz., external arguments) outside the latter's maximal projection. If every XP (except for VP) is a phase, $w h$-movement must proceed via every $\mathrm{XP}$ to its ultimate target position (the $\mathrm{C}_{[\bullet \text { wh॰ }}$ node that attracts it). ${ }^{21}$

Based on this notion of phase, Phase Balance and the PIC interact as shown in (24) to generate the derivation of a simple embedded wh-question like what John read. On the vP cycle, what must move to a specifier because

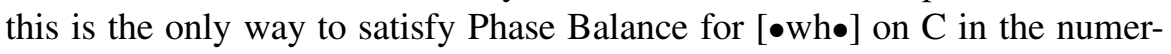
ation; $[\bullet \mathrm{D} \bullet]$ on $\mathrm{T}$ in the numeration has a similar requirement, which is met trivially by the external argument (but see below); furthermore, $\mathrm{V}$ moves to $\mathrm{v}$, an operation that I assume to take place without exception (due to the deficient character of VP). Next, on the TP cycle the same reasoning applies with

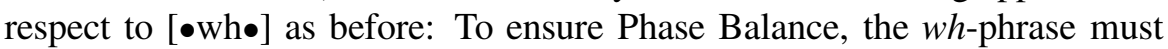
be moved to T's specifier, even though this movement is not feature-driven and thus violates the Last Resort condition (in addition, the external argument moves to SpecT, as an instance of feature-driven movement). Finally, on the $\mathrm{CP}$ cycle, the $w h$-phrase moves to SpecC, triggered not by Phase Balance,

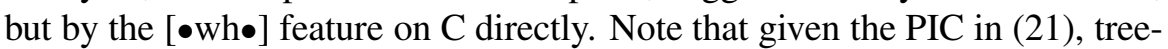
internal search space is constantly reduced in this derivation (this is indicated by striking through the domains that have become inaccessible in (24)): On the TP cycle, the complement domain of vP is not accessible anymore; and on the $\mathrm{CP}$ cycle, $\mathrm{vP}$ is invisible for syntactic operations.

(24) (I wonder) what John read

a. [vP what $\left.\mathrm{John}_{2} \mathrm{v}+\mathrm{read}_{3}\left[\mathrm{vP}_{3} \mathrm{t}_{1}\right]\right]$

b. [TP what $\left.\mathrm{John}_{2} \mathrm{~T}\left[\mathrm{vP} \mathrm{t}_{1}^{\prime} \mathrm{t}_{2} \mathrm{v}+\mathrm{read}_{3}\left[\mathrm{t}_{3} \mathrm{t}_{1}\right]\right]\right]$ $\rightarrow$ workspace: $\left\{\mathrm{C}_{[\bullet \text { wh॰ }}, \mathrm{T}_{[\bullet \mathrm{D} \bullet]}\right\}$

${ }^{20}$ Similar considerations may apply with respect to NP if there is an nP/NP distinction; see, e.g., Adger (2003).

${ }^{21}$ There are many predecessors of this approach; see van Riemsdijk (1978), Koster (1978), Sportiche (1989), Takahashi (1994), Agbayani (1998), Bošković (2002a), Boeckx (2003), and Chomsky (2005b). Similar concepts are employed in the SLASH feature percolation analysis of $w h$-movement employed in GPSG (see Gazdar (1981), Gazdar et al. (1985)), and in Koster's (2000) approach in terms of feature percolation in gap phrases. Also compare the remark that "phases should be as small as possible, to minimize memory for [spell-out]" in Chomsky (2001a). - Chomsky (2001b) argues that phases must be somewhat larger objects based on Agree relations holding between T and a VP-internal object (as in nominative object constructions in Icelandic). In the present approach, Agree will have to be successive-cyclic, just like movement. Also see Fischer (2004) for the same consequence with respect to binding. 


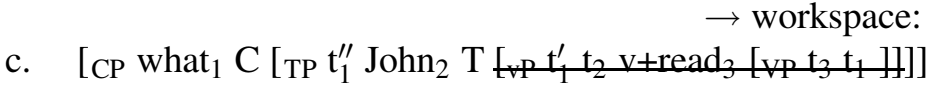

$\rightarrow$ workspace: $\left\{\mathrm{C}_{[\bullet \text { wh॰ }}\right\}$

$\rightarrow$ workspace: $\{-\}$

This may suffice as a brief illustration of the Phase Balance approach to successive-cyclic movement. There are two consequences of this analysis that will prove important for the approach in terms of relativized linearization that is developed in the next section: First, there are now two types of movement that can be clearly distinguished: On the one hand, there is featuredriven movement; on the other hand, there is movement that is brought about by Phase Balance. This difference will make it possible to relativize ordering statements. Second, in interaction with the narrow concept of phases employed here, the PIC drastically reduces search space. This opens up the possibility that ordering statements that were generated at some earlier point in the derivation can be forgotten at later stages because they are rendered invisible by the PIC.

With this approach to successive cyclicity as background, let me now turn to the system of relativized linearization itself.

\section{Relativized Linearization}

\subsection{Analysis}

Suppose first that syntactic representations do not tolerate contradictory ordering statements, exactly as assumed by Fox and Pesetsky (2003, 2005a,b). However, note that this does not imply that contradictory ordering statements can never be generated in the course of the derivation. Contradictory statements $\alpha<\beta$ and $\beta<\alpha$ can be generated under this assumption as long as only one of the two statements is accessible in the syntax at any given point of the derivation. Syntactic inaccessibility of an ordering statement follows from cyclic spell-out: As soon as a phase is completed, the domain of its head, including all ordering statements generated for this domain, is spelled out and thus rendered inaccessible for further syntactic operations, in accordance with the PIC. This opens up the possibility of a new, contradictory statement being generated in the syntax. When this statement is sent to phonology, it replaces the older, contradictory one there (i.e., whereas syntax does not permit contradictory ordering statements, phonology can handle this situation by deleting the older statement). Thus, it is the fact that information can be lost in the course of the derivation (which in turn is a characteristic property of derivational systems) that makes it possible to assume that con- 
tradictory ordering statements can arise in syntax.

Next, the question arises of when and how ordering statements are generated. I assume that the domain in which ordering statements are generated is extremely local: It is the syntactic Merge operation. ${ }^{22}$ The ordering statements themselves are generated according to precedence rules which are partly language-specific; e.g.: A head precedes its complement in English; a head follows its complement in Korean; and a [+V] head (V, v, A, T) follows its complement, whereas a $[-\mathrm{V}]$ head $(\mathrm{N}, \mathrm{D}, \mathrm{P}, \mathrm{C})$ precedes its complement in German. Crucially, now, ordering statements are relativized, in the sense that only a subset of the ordering statements that could in principle be generated are in fact generated by syntactic operations. The underlying hypothesis is that the system of cyclic spell-out exhibits optimal design: Given the ubiquity of displacement operations in syntax, a system of cyclic spell-out that does not take this into account by selectively ignoring possible ordering statements that will invariably have to be undone (because an item that participates in the ordering relation will subsequently have to move and thereby likely reverse the original order) would exhibit poor design. ${ }^{23}$ Thus, I would like to suggest that a Merge operation applying to two categories $\alpha$ and $\beta$ generates a linearization statement for $\alpha$ and $\beta$, and for items that are dominated by $\alpha$ or $\beta$, except for those categories that involve a difference in Merge status. To see how this systems works, consider first two general constraints that are standardly taken to govern syntactic linearization: the Exclusivity Condition in (25-a) and the Nontangling Condition in (25-b) (see Partee et al. (1993, 440)).

(25) a. Exclusivity Condition:

In any well-formed constituent structure tree, for any nodes $\mathrm{x}$ and $\mathrm{y}, \mathrm{x}$ and $\mathrm{y}$ stand in the precedence relation $\mathrm{P}$ (i.e., either $<\mathrm{x}, \mathrm{y}\rangle \in$ $\mathrm{P}$ or $<\mathrm{y}, \mathrm{x}>\in \mathrm{P}$ ) iff $\mathrm{x}$ and $\mathrm{y}$ do not stand in the dominance relation $\mathrm{D}$ (i.e., neither $<\mathrm{x}, \mathrm{y}>\in \mathrm{D}$ nor $<\mathrm{y}, \mathrm{x}>\in \mathrm{D}$ ).

b. Nontangling Condition:

In any well-formed constituent structure tree, for any nodes $\mathrm{x}$ and $\mathrm{y}$, if $\mathrm{x}$ precedes $\mathrm{y}$, then all nodes dominated by $\mathrm{x}$ precede all nodes dominated by $\mathrm{y}$.

In the present analysis, the incompatibility of dominance and precedence expressed by the Exclusivity Condition follows from the fact that ordering statements are tied to Merge operations, which do not involve dominance; the total

\footnotetext{
${ }^{22}$ See Epstein and Seely (2002) for a related but more general assumption.

${ }^{23}$ Also compare the discussion of generalization (I) in Chomsky (2005a, 21).
} 
ordering of terminals implied in the Exclusivity Condition follows because, at the end of the derivation, all categories will have participated in ordering statements. As for the Nontangling Condition, I will assume that, while basically valid, it does not hold without exception; the instances where it does not hold in the derivation are accounted for by the concept of relativized linearization, to which I now turn.

\section{(26) Relativized Linearization:}

For all categories $\mathrm{x}$ reflexively dominated by a category $\alpha$ and for all categories y reflexively dominated by a category $\beta$, Merge $(\alpha, \beta)$ generates an ordering statement for $<\mathrm{x}, \mathrm{y}>$ if $\mathrm{x}$ and $\mathrm{y}$ have an identical Merge status.

The final notion to be clarified here is the concept of "identical Merge status." At this point, the approach to successive-cyclic movement sketched in section 4 becomes important. In this approach, it is possible to formally distinguish between feature-driven and non-feature-driven Merge and Move operations; and this is what underlies the differences in Merge status. Thus, I assume that there are two types of Merge status: A category $\alpha$ has Merge status [+ $\psi]$ at a given stage of the derivation if the reason why it shows up in its present position is related to a feature in the local environment, and $\alpha$ has Merge status $[-\psi]$ at a given stage of the derivation if the reason why it shows up in its present position is related to a feature that is not present in the local environment (but that exists in the numeration). External, basic Merge patterns with $[+\psi]$-marked internal Merge (i.e., Move), and so it would seem natural to assume that external Merge is feature-driven. I will indeed presuppose that this is the case (see Svenonius (1994), Collins (2003), Adger (2003), Stabler (1996, 1997, 1998), Kobele (2006), Sternefeld (2006), and Heck and Müller (2006b), among others, for arguments to this effect): External Merge is triggered by subcategorization features $[\bullet \mathrm{F} \bullet$ ] on heads that act as probes, just as with feature-driven internal Merge.

Closer inspection reveals that a bit more must be said about the Merge status of categories that are dominated by a category that has been merged $(\alpha)$ : On the one hand, it may be that a category $\gamma$ included in a category $\alpha$ that undergoes feature-driven Merge has itself undergone non-feature-driven movement in $\alpha$; in that case, $\gamma$ clearly has a different Merge status. On the other hand, it may be that $\gamma$ has undergone feature-driven movement in $\alpha$ (or no movement at all), whereas $\alpha$ is moved solely for reasons of Phase Balance; in this case, however, $\gamma$ must have the same Merge status as $\alpha$ (its position is not fixed with respect to $\alpha$-external material). The notion of Merge status 
can thus be defined as in (27) (where a non-local feature is a feature that is not part of the current tree). ${ }^{24}$

(27) Merge status:

a. A category $\gamma$ in a position $\mathrm{P}$ has Merge status $[-\psi]$ iff (i) or (ii):

(i) $\gamma$ is merged in $\mathrm{P}$, and $\gamma$ is required in $\mathrm{P}$ by a non-local Mergeinducing feature.

(ii) $\gamma$ is dominated by (a segment of) a category with Merge status $[-\psi]$.

b. A category $\gamma$ in a position $\mathrm{P}$ has Merge status $[+\psi]$ iff (i) and (ii):

(i) $\gamma$ is merged in $\mathrm{P}$, and $\gamma$ is not required in $\mathrm{P}$ by a non-local Mergeinducing feature.

(ii) $\gamma$ is not dominated by a (segment of a) category with Merge status $[-\psi]$.

(27) predicts a complementary distribution of Merge status [+ $\psi]$ and Merge status $[-\psi]$ among the positions that are generated by Merge (see below on adjunction). However, there are two kinds of positions that (27) systematically classifies as $[-\psi]$ even though they are base positions (and should thus arguably be $[+\psi]$ ). First, this holds for a Specv position in which an external argument is merged that will undergo raising to SpecT; and second, it holds for all heads that need to undergo movement to a higher head. This would imply that subjects (that will move) and heads (that will move) never participate in linearization statements in their base positions. To avoid this consequence, two additional assumptions are necessary. As for subjects, I will deviate from the standard assumption that the external argument's base position is a position that is accessible to the next higher phase; i.e., that this position is part of the edge of vP. More generally, suppose that phase edges must be derived positons, in the sense that they can only be reached by movement, as in (28).

\section{(28) Edge:}

A category is part of the edge of a phase iff it is a specifier of a phase head that is created by Move.

\footnotetext{
${ }^{24} \mathrm{~A}$ remark is due on the ontological status of $[+\psi]$ and $[-\psi]$. These symbols do not act as genuine features that encode pieces of information (even though I will sometimes say that a category is 'marked' $[+\psi]$ or $[-\psi]$ ); their only purpose is to simplify exposition. This should be particularly evident when categories change their $[ \pm \psi]$ status in the derivation, but it holds throughout: Whether a category has Merge status $[+\psi]$ or $[-\psi]$ can always be inspected by looking at the syntactic context; this is not information that exists independently on the category. Thus, there is no violation of the Inclusiveness Condition here (see Chomsky (2001b)).
} 
Given (28), the PIC requires movement of an external argument from an inner to an outer specifier of $\mathrm{v}$, and this movement may often be string-vacuous. By adopting (28), Specv ceases to be exceptional with respect to edge properties (other escape hatches of phases - e.g., SpecT, SpecC - are reached by internal rather than external Merge). ${ }^{25}$

Turning next to heads, the situation is slightly different because heads cannot undergo successive-cyclic movement, assuming excorporation (at least of the type that would be required here) to be impossible (see Baker (1988), Roberts (1991) for relevant discussion). So it seems that if heads are to participate in the $[+\psi] /[-\psi]$ system at all, they have to do so in situ. What we want is that a head may be $[+\psi]$ (so that it can generate linearization statements with externally merged items) and also $[-\psi]$ (if it is to undergo movement to a higher head). Assuming that heads can be $[+\psi] /[-\psi]$ at the same time will not help because they would then never have a Merge status that is identical to that of either a $[-\psi]$-marked or a $[+\psi]$-marked element. The solution that I would like to propose in view of this is that heads always start out as $[+\psi]$ and may then change their Merge status to $[-\psi]$ under the conditions regulated by (27), but only if they have discharged all their subcategorization features (and thereby lost their 'base property'); see (29), which acts as an addition to (27-a-i).

(29) A head can only have Merge status $[-\psi]$ if its subcategorization features have all been discharged; otherwise it has Merge status $[+\psi]$.

It now remains to be shown how this revised approach to cyclic linearization can account for the shape conservation effects discussed in this paper without incurring the problems mentioned in section 3 above. I will do this in the next subsection.

\subsection{Sample Derivatons}

\subsubsection{Abstract Scenarios}

Consider the abstract representation in (30), which results from a derivational step where an XP $\alpha$ is merged with another XP $\beta$, yielding $\omega$ (headed by $\alpha$ or $\beta$ ), with $\delta_{1}, \ldots, \delta_{n}$ the categories dominated by $\alpha$ and $\gamma_{1}, \ldots, \gamma_{m}$ the categories dominated by $\beta$.

(30) $\left[_{\omega}\left[{ }_{\alpha} \delta_{1}, \ldots, \delta_{n}\right]\left[{ }_{\beta} \gamma_{1}, \ldots, \gamma_{m}\right]\right]$

\footnotetext{
${ }^{25}$ Independent arguments for (28) are given in Heck and Müller (2006a).
} 
In (30), $\alpha$ and $\beta$ may have an identical Merge status [+ $\psi]$; they may in principle have an identical Merge status $[-\psi]$ (although this state of affairs is independently excluded on general grounds, at least as long as interarboreal operations are ruled out); or they may differ in Merge status $([+\psi] /[-\psi])$. In the first two cases, an ordering statement is generated for $\alpha$ and $\beta$; in the last case, no ordering statement is generated for $\alpha$ and $\beta$. Note, however, that categories $\delta_{i}$ and $\gamma_{j}$ do not necessarily participate in the same ordering statements as $\alpha$ and $\beta ; \delta_{i}$ may have a Merge status different from $\alpha$, and $\gamma_{j}$ may have a Merge status different from $\beta$ (at least as long $\alpha, \beta$ do not have status $[-\psi])$. Thus, it may well be the case that, e.g., $\alpha$ and $\beta$ have Merge status $[+\psi]$, whereas some $\gamma_{j}$ in $\beta$ has Merge status $[-\psi]$, which then prevents $\gamma_{j}$ from participating in an ordering statement. (An instantiation of this abstract situation would be Merge (T,vP), with $\mathrm{T}$ and $\mathrm{vP}$ marked $[+\psi]$, and $\mathrm{vP}$ including a $w h$-phrase in its (outer) specifier that has undergone non-feature-driven movement, and therefore has Merge status [- $\psi]$.) Moreover, both $\delta_{i}$ and $\gamma_{j}$ may in principle have Merge status $[-\psi]$ even though their dominating categories $\alpha$ and $\beta$ have Merge status $[+\psi] .{ }^{26}$ With this background, let me now turn to derivations of actual sentences.

\subsubsection{Simple Clauses}

Consider first simple English sentences like those in (31).

(31) a. [СР C [TP Mary ${ }_{1}\left[\mathrm{vP}_{1}^{\prime} \mathrm{t}_{\mathrm{v}^{\prime}} \mathrm{t}_{1}\right.$ wrote $_{2}-\mathrm{v}$ [vP $\mathrm{t}_{2}$ a book ]]]]]

b. [CP C [TP John $1\left[\mathrm{vP}_{1}^{\prime} \mathrm{t}_{1}^{\prime} \mathrm{v}^{\prime} \mathrm{t}_{1} \mathrm{gave}_{2}-\mathrm{v}\left[\mathrm{vP}\left[\mathrm{DP}_{3}\right.\right.\right.$ Mary $]\left[\mathrm{v}^{\prime} \mathrm{t}_{2}\left[\mathrm{DP}_{4} \mathrm{a}\right.\right.$ book] ]]]]]]

I have argued above that VP is a defective projection (and therefore not a phase). The conclusion that VP is special is reinforced by considerations related to cyclic linearization. If Merge of V and DP (in (31-ab)), or of $\mathrm{V}^{\prime}$ and DP (in (31-b)), generates ordering statements, subsequent obligatory movement of $\mathrm{V}$ to $\mathrm{v}$ will invariably generate contradictory ordering statements in the second case, which will then lead to a crash of the derivation. This outcome can be avoided if VP is defective with respect to linearization statements, just as it is defective with respect to phase status. Thus, I would like to conclude that no ordering statements are generated in the VP that involve V; the underlying rationale is that $\mathrm{vP}$ and $\mathrm{VP}$ act in certain respects like a single

\footnotetext{
${ }^{26}$ Relevant constructions may well exist, in violation of Gazdar's (1981) one hole restriction on syntactic dependencies; see Pesetsky (1982) for relevant discussion. Furthermore, parasitic gaps would instantiate such a case, under some analyses.
} 
projection, and the position occupied by $\mathrm{V}$ after head movement to $\mathrm{v}$ is the one that determines base linearization. With this in mind, consider (31-b).

On the VP cycle, there are ordering statements $\mathrm{DP}_{3}<\mathrm{V}^{\prime}$ and, accordingly, $\mathrm{DP}_{3}<\mathrm{DP}_{4}$ after Merge of $\mathrm{DP}_{3}$, plus further statements triggered by (26); however, by stipulation, there is no statement $\mathrm{DP}_{3}<\mathrm{V}$. $\mathrm{DP}_{3}, \mathrm{~V}^{\prime}$ and $\mathrm{DP}_{4}$ have the same Merge status $[+\psi]$ because they have undergone (featuredriven) external Merge. Next, $v$ is merged with VP and attracts V; both operations are driven by probe features on $\mathrm{v}$ (for subcategorization and movement, respectively). This generates the ordering statement $\mathrm{V}+\mathrm{V}<\mathrm{VP}$, and also $\mathrm{V}+\mathrm{v}$ $<\mathrm{DP}_{3}$, and $\mathrm{V}+\mathrm{v}<\mathrm{DP}_{4}$ because all these categories have the same Merge status $[+\psi]$. In the next step, the external argument $\mathrm{DP}_{1}$ is merged as v's specifier, which generates the ordering statement $\mathrm{DP}_{1}<\mathrm{v}^{\prime}$, and also $\mathrm{DP}_{1}<\mathrm{V}+\mathrm{v}$, $\mathrm{DP}_{1}<\mathrm{DP}_{3}$, and $\mathrm{DP}_{1}<\mathrm{DP}_{4}$. Thus, all external Merge operations affecting $\mathrm{vP}$ are completed, and v does not bear a probe feature anymore. Given (29), this means that $\mathrm{v}$ may in principle now acquire Merge status $[-\psi]$; however, it does not do so in the case at hand because English does not have V+v-to-T movement (i.e., $\mathrm{T}$ does not have a probe feature attracting $\mathrm{V}+\mathrm{v}$; hence, $\mathrm{V}+\mathrm{v}$ is not required in its position by a non-local feature).

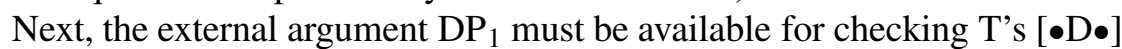
feature. Given the assumption that phase edges can only be reached by movement (see (28)), an external argument that is required in the edge domain by

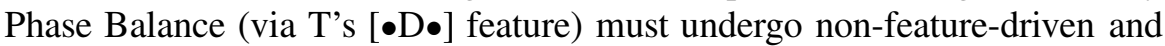
(in the case at hand) string-vacuous movement to an outer specifier of $\mathrm{vP}$ (this is indicated by the intermediate traces $t_{1}^{\prime}$ in (31)). In this case, no new ordering statement is generated because the moved external argument is $[-\psi]$, and the $\mathrm{v}^{\prime}$ category it is merged with is $[+\psi]$ (furthermore, in the present case, there is no other category within $\mathrm{v}^{\prime}$ that is $[-\psi]$, which would generate an ordering statement with the external argument). This completes the vP in (31); the domain of $\mathrm{v}$ then undergoes spell-out, and the ordering statements generated in this domain become inaccessible (and irrelevant) for the remainder of the derivation.

After this, $\mathrm{T}$ is merged with $\mathrm{vP}$; both categories have Merge status $[+\psi]$, and this generates some ordering statements, all of them straightforward. ${ }^{27}$ However, at this point, no ordering statement is generated for $\mathrm{T}([+\psi])$ and the

\footnotetext{
${ }^{27}$ Of course, ordering statements can be generated via (26) only for those categories that are still accessible in the structure (i.e., that have not yet undergone cyclic spell-out). To ensure a total order of terminals in the PF component, missing statements are added there according to the Nontangling Condition, which ensures transitivity; this process overwrites contradictory earlier statements, as stated above.
} 
external argument $\mathrm{DP}_{1}([-\psi])$. The next operation is subject raising to $\mathrm{SpecT}$, driven by $[\bullet \mathrm{D} \bullet]$ on $\mathrm{T}$. Now, an ordering statement is generated for $\mathrm{DP}_{1}([+\psi])$ and $\mathrm{T}^{\prime}([+\psi])$, and for $\mathrm{DP}_{1}$ and all other categories in $\mathrm{T}^{\prime}$ (because the latter are all marked $[+\psi])$. In principle, the new ordering statements thus generated could now contradict earlier ones (which are rendered inaccessible by spellout of the earlier vP phase); but since the external argument preceded all vPinternal items in the first place, contradicting ordering statements do not arise (but see subsection 5.2.8 below on passive and raising constructions). After this, the domain of $\mathrm{T}$ is spelled out, and the next phase head $(\mathrm{C})$ is merged with TP. Ordering statements for $\mathrm{C}([+\psi])$ and TP $([+\psi])$ (as well as material within TP) are generated, but there are no interesting further consequences.

\subsubsection{Wh-Movement}

Consider next a simple case of $w h$-movement, as in (32):

(32) (I wonder) [CP what 2 C [TP $\mathrm{t}_{2}^{\prime \prime} \operatorname{Mary}_{1} \mathrm{~T}\left[\mathrm{vPP}_{1}^{\prime} \mathrm{t}_{\mathrm{v}^{\prime}} \mathrm{t}_{2}^{\prime}\left[\mathrm{v}^{\prime} \mathrm{t}_{1}\right.\right.$ saw $\left.\left.\left.\left.\left.\mathrm{t}_{2}\right]\right]\right]\right]\right]$

On the vP level, the main difference to (31) is that both the external argument $\mathrm{DP}_{1}$ and the internal argument $\mathrm{DP}_{2}$ are required in the edge domain of vP by Phase Balance (for $[\bullet \mathrm{D} \bullet]$ on $\mathrm{T}$ and $[\bullet w h \bullet]$ on $\mathrm{C}$, respectively). External Merge of $\mathrm{DP}_{1}([+\psi])$ and $\mathrm{v}^{\prime}([+\psi])$ inter alia generates a statement $\mathrm{DP}_{1}<$ $\mathrm{DP}_{2}$; subsequent non-feature-driven movement of $\mathrm{DP}_{1}([-\psi])$ and $\mathrm{DP}_{2}([-\psi])$ to outer specifiers of $\mathrm{v}^{\prime}$ generates a new ordering statement. If the two DPs reassemble in their base order, as in (32), no contradictory ordering statement is generated: First, movement of $\mathrm{DP}_{2}$ across $\mathrm{DP}_{1}$ (which is in its base position) does not generate a new ordering statement because $\mathrm{DP}_{2}$ is $[-\psi]$ and $\mathrm{DP}_{1}$ is $[+\psi]$; and second, subsequent movement of $\mathrm{DP}_{1}$ across $\mathrm{DP}_{2}$ reproduces the earlier ordering statement (both are $[-\psi]$ now). However, if they reassemble in the edge domain in the reversed order, a new, contradictory ordering statement $\mathrm{DP}_{2}<\mathrm{DP}_{1}$ is generated. This latter ordering statement would lead to a crash of the derivation because the earlier ordering statement $\mathrm{DP}_{1}<\mathrm{DP}_{2}$ is still accessible at this point of the derivation. Of course, this theoretical prediction does not yet have empirical consequences: It is hard to see how the two derivations of (32) - with $\mathrm{DP}_{1} \mathrm{vs}$. $\mathrm{DP}_{2}$ as the highest specifier of $\mathrm{vP}-$ could be empirically distinguished. However, I will show below that there are contexts where different empirical predictions do arise. For the time being, we can conclude that the vP phase is thereby finished, and the complement of $\mathrm{v}$ is spelled out, together with the linearization statements established in the domain of $\mathrm{vP}$. 
On the TP level, $\mathrm{DP}_{1}$ undergoes raising to SpecT (after Merge (T,vP), which can be neglected here) and, having acquired Merge status [+ $\psi]$, induces ordering statements with $\mathrm{T}^{\prime}([+\psi])$ and $[+\psi]$-marked categories included in $\mathrm{T}^{\prime}$; crucially, no statement is generated by Merge of $\mathrm{DP}_{1}$ and $\mathrm{T}^{\prime}$ for $\mathrm{DP}_{1}$ in SpecT $([+\psi])$ and $\mathrm{DP}_{2}$ in Specv $([-\psi])$. Next, $\mathrm{DP}_{2}$ moves to an outer specifier of $\mathrm{T}$; this movement is not feature-driven but forced by Phase Balance. No new ordering statement is generated by this Merge operation because $\mathrm{DP}_{2}$ in SpecT is $[-\psi]$ and its sister $\mathrm{T}^{\prime}$ and all categories included in $\mathrm{T}^{\prime}$ have Merge status $[+\psi]$. After this, the domain of $\mathrm{T}$ is spelled out, and the only ordering statements that are still accessible in the derivation are $\mathrm{DP}_{1}<$ $\mathrm{T}^{\prime}$ and $\mathrm{DP}_{1}<\mathrm{T}$ (since $\mathrm{T}$ is phonologically empty, this can never be relevant).

On the $\mathrm{CP}$ cycle, $\mathrm{DP}_{2}$ undergoes feature-driven movement to SpecC. This generates the ordering statement $\mathrm{DP}_{2}<\mathrm{DP}_{1}$ (among others). Note that this contradicts the earlier ordering statement(s) $\mathrm{DP}_{1}<\mathrm{DP}_{2}$ generated on the vP cycle. However, this is unproblematic because cyclic spell-out has long removed the conflicting linearization information from the derivation; and phonology, by assumption, resolves the conflict by simply replacing the earlier statement with the new one.

After these general illustrations, I will now return to the original idea that Holmberg's Generalization can be derived from cyclic linearization, and show how this follows in the present approach.

\subsubsection{Simple Object Shift}

Recall Sells' (2001) and Richards' (2004) insight that the shape conservation property of object shift is due to the strict locality of the operation. In the present approach, this translates into a generation of an ordering statement that contradicts an earlier ordering statement which is still present in the derivation. For concreteness, I assume that object shift is feature-driven movement to Specv. ${ }^{28}$ This implies that negation and those adverbials which are crossed by object shift show up in specifier positions of $\mathrm{v}$, and do not head

\footnotetext{
${ }^{28}$ For present purposes, this feature can be referred to as $[\pi]$; and it can be further assumed that a $[\bullet \pi \bullet]$ feature is inserted on $\mathrm{v}$ in the numeration (see Chomsky $(2000,2001 \mathrm{~b}$ )) - obligatorily so for every [D] that is an unstressed pronoun argument of V in Danish and Icelandic, and optionally so for other [D] arguments in Icelandic. Under these assumptions, more must eventually be said to capture the fact that unstressed pronouns are possible in situ when verb movement is not possible, as in (6-c). However, I will not explore these matters here any further since they are independent of the main issues currently under consideration: The only important assumption is that an object-shifted DP has Merge status $[+\psi]$ rather than Merge status $[-\psi]$, and this should be uncontroversial.
} 
functional projections that intervene between $\mathrm{T}$ and $\mathrm{v}$ in the main clausal projection line (see Bobaljik (2002), Thráinsson (2007) vs. Alexiadou (1997), Cinque (1999)). ${ }^{29}$

Consider now first licit cases of object shift accompanied by main verb raising, as in the Danish example (6-b), which is repeated here as (33) (with structural information added).

$$
\begin{aligned}
& \text { [CP Hvorfor købte [TP Peter } 2 t_{\mathrm{V}+\mathrm{v}+\mathrm{T}}^{\prime}\left[{ } _ { \mathrm { vP } } \mathrm { t } _ { 2 } ^ { \prime } \left[\mathrm { v } _ { \mathrm { v } ^ { \prime } } \left[\mathrm{DP}_{1}\right.\right.\right. \text { den ] } \\
& \text { why bought Peter it } \\
& \left.\left.\left.\left.\left[\mathrm{v}^{\prime} \text { ikke }\left[\mathrm{v}^{\prime} \mathrm{t}_{2}\left[\mathrm{v}^{\prime} \mathrm{t}_{\mathrm{V}+\mathrm{v}}\left[\mathrm{vP} \mathrm{t}_{\mathrm{v}} \mathrm{t}_{1}\right]\right]\right]\right]\right]\right]\right]\right] \text { ? } \\
& \text { not }
\end{aligned}
$$

On the $\mathrm{vP}$ cycle, an ordering statement $\mathrm{V}+\mathrm{v}<\mathrm{DP}_{1}$ is generated after $\mathrm{v}$ has been merged with VP and $\mathrm{V}$ has undergone head movement to v. The external argument is merged, negation is added, and both operations trigger ordering statements with $\mathrm{v}^{\prime}$ and the categories included therein (because so far, all categories are marked $[+\psi]$ ). Next, the following two movement operations apply: There is non-feature-driven movement of the external argument $\mathrm{DP}_{2}$ to an outer specifier, forced by Phase Balance (for the $[\bullet \mathrm{D} \bullet$ ] feature of $\mathrm{T}$ in the numeration), and there is feature-driven object shift of the internal argument $\mathrm{DP}_{1}$ to an outer specifier as well. The Strict Cycle Condition essentially demands that every XP movement operation extends the tree created so far; however, head movement (see Chomsky (1993)) does not fall under this constraint. In addition, it has often been argued that movement to a nonunique (multiple) specifier may minimally violate the Strict Cycle Condition by ending up in lower specifier position ('tucking in'; see Richards (2001)). Assuming this latter option, the present system is compatible both with two derivations of (33). In both of them, the external argument $\mathrm{DP}_{2}$ must move first, acquiring status $[-\psi]$ in the process, which precludes a generation of ordering statements with any category in its sister $\mathrm{v}^{\prime}$. If, alternatively, the internal argument $\mathrm{DP}_{1}$ moves first to Specv, both $\mathrm{DP}_{1}$ (in the object shift position, where it is required by a local probe feature on v, viz., the object shift-triggering feature $[\bullet \pi \bullet]$ ) and $\mathrm{DP}_{2}$ (in situ) are marked $[+\psi]$, and this movement operation then leads to a crash of the derivation because the new

\footnotetext{
${ }^{29}$ There are two implicit assumptions here: First, adverbials can only enter the structure if all subcategorization features of a head have been discharged. And second, internal Merge operations follow (i) external, feature-driven Merge operations and (ii) adverb insertion. If there is no movement to a position below a base position (but see the main text on movement to a position below a derived position), a moved object will invariably end up in a higher specifier than an adverbial.
} 
ordering statement $\mathrm{DP}_{1}<\mathrm{DP}_{2}$ contradicts the earlier (and still accessible) statement $\mathrm{DP}_{2}<\mathrm{DP}_{1}$. Thus, Phase Balance-driven movement of $\mathrm{DP}_{2}$ to Specv has to apply first. The question then is which Specv position is targetted by subsequent object shift of the internal argument $\mathrm{DP}_{1}$. Given present assumptions, $\mathrm{DP}_{1}$ may either move to a Specv position above $\mathrm{DP}_{2}$, or to a Specv position below $\mathrm{DP}_{2}$, as an instance of tucking in (but above the adverb) - since $\mathrm{DP}_{2}$ is now $[-\psi]$, and $\mathrm{DP}_{1}$ is $[+\psi]$, no new statement is generated in either case. The structure in (33) represents the latter option, with tucking in of the shifted object, but I see no reason to rule out the former. ${ }^{30}$

When $\mathrm{DP}_{1}$ undergoes object shift to Specv, it (potentially) crosses (or affects, see the last footnote) three categories containing lexical material $-\mathrm{DP}_{2}$ (in one derivation), adverb, and $\mathrm{V}+\mathrm{v}-$, and for each of these categories, it must be shown that no contradictory ordering statement is generated. This is evident for $\mathrm{DP}_{2}$ : $\mathrm{DP}_{1}([+\psi])$ and $\mathrm{DP}_{2}([-\psi])$ differ in Merge status. What about the adverb ikke? It is often assumed that adverbial categories do not enter syntactic derivations as a result of feature-driven Merge operations since it does not seem plausible to assume that the discharge of a subcategorization probe feature (on either the modified category or the adverbial category itself) can be involved here; in fact, it is sometimes postulated that adverbial categories do not enter phrase markers by Merge in the first place, but by some alternative structure-building operation (Adjoin; cf. Chomsky (2000, 2001b), Adger (2003), among others). I will here follow this latter proposal and assume that adverbs are integrated into syntactic representations by a separate operation Adjoin. Adjoin is not feature-driven and follows all external Merge operations that are triggered by subcategorization features of a head X in an XP; but, crucially, Adjoin precedes all internal Merge operations (feature-driven or not). Since adverbial categories do not enter the structure by Merge, they have neither Merge status $[+\psi]$ nor Merge status $[-\psi]$ (as long as they stay in situ). This means that they cannot participate in ordering statements generated via (26) at all unless they undergo movement (featuredriven or non-feature-driven). Consequently, when the adverb ikke is merged, no linearization statement with $\mathrm{DP}_{1}$ (or any other category) is generated; and the same goes for movement of $\mathrm{DP}_{1}$ across the adverb. ${ }^{31}$

\footnotetext{
${ }^{30}$ Given the option of tucking in, relativized linearization (see (26)) must be modified in such a way that movement of a category $\alpha$ to a lower derived specifier may still trigger an ordering statement with a category $\beta$ in a higher specifier of the same head. This is completely parallel to the modification of the Strict Cycle Conditon that tucking in necessitates.

${ }^{31}$ The question arises of how adverbial categories can then ultimately be linearized with respect to other categories. For present purposes, it may suffice to assume that ordering state-
} 
With $\mathrm{DP}_{2}$ (Peter) and the intervening adverb (ikke) now accounted for, the final and most important question is why movement of $\mathrm{DP}_{1}$ across $\mathrm{V}+\mathrm{v}$ (købte) does not trigger a new ordering statement $\mathrm{DP}_{1}<\mathrm{V}+\mathrm{v}$, which would contradict the one established earlier, viz., $\mathrm{V}+\mathrm{v}<\mathrm{DP}_{1}$. The answer is given by (29): When $V+v$ has discharged all its subcategorization probe features (i.e., after external, feature-driven Merge of $\mathrm{DP}_{2}$ ), it can in principle acquire Merge status $[-\psi]$, thereby losing Merge status $[+\psi]$. In the case at hand, $\mathrm{V}+\mathrm{v}$ does in fact now obtain Merge status $[-\psi]$ because it is required in its position by a probe feature of $\mathrm{T}$ (which is still in the numeration at this point); this probe feature $([\bullet \bullet \bullet])$ will trigger head movement on the next cycle. Since $\mathrm{V}+\mathrm{v}$ is marked $[-\psi]$ immediately after the external argument is merged, object shift of $\mathrm{DP}_{1}$ to an outer specifier of $\mathrm{v}$ gives rise to the following situation: $\mathrm{DP}_{1}$ is marked $[+\psi], \mathrm{V}+\mathrm{v}$ is marked $[-\psi]$. The Merge status of $\mathrm{DP}_{1}$ and the Merge status of $\mathrm{V}+\mathrm{v}$ are therefore not identical, and no new ordering statement is generated by the operation. More generally, then, object shift as in (33) never leads to contradictory ordering statements when the derivation "knows" that the finite verb will have to move later in the derivation (and will thereby invariably have to end up in front of the shifted object, given that $\mathrm{T}$ precedes its complement). ${ }^{32}$

Turning now to illicit cases of object shift that are not accompanied by verb movement to a higher position, the crucial difference between the $\mathrm{vP}$ of a sentence like (6-d), repeated here as (34), and the vP of a sentence like (6-b) $(=(33))$ is that $\mathrm{v}$ is non-finite in (34), and does not undergo movement to $\mathrm{T}$ on the next cycle. More technically, $\mathrm{v}$ is not required in its position by $\mathrm{T}$ because $\mathrm{T}$ does not have $\mathrm{a}[\bullet \bullet \bullet]$ probe feature in this derivation. Consequently, $\mathrm{v}$ never acquires Merge status $[-\psi]$ in (34). Therefore, with both items marked $[+\psi]$, object shift of $\mathrm{DP}_{1}$ creates an ordering statement $\mathrm{DP}_{1}<\mathrm{V}+\mathrm{v}$, which contradicts the earlier (and still syntactically accessible) statement $\mathrm{V}+\mathrm{v}<$ $\mathrm{DP}_{1}$. This leads to a crash of the derivation.

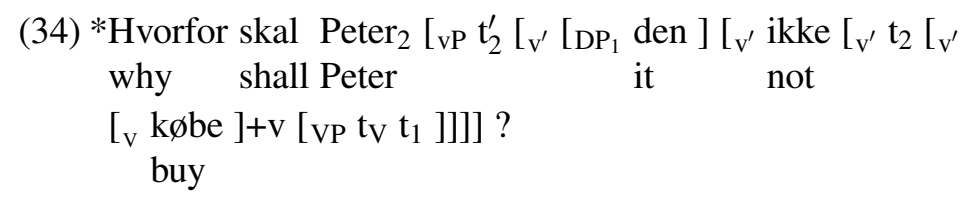

ments for an adverbial category (that is not part of the edge domain of a phase) are generated when a phase is complete, and the adverbial then undergoes spell-out together with the rest of the domain of the head of the phase.

${ }^{32}$ The same account suggests itself for cases where the verb ends up in front of an object-shifted pronoun by topicalization rather than head movement; see Holmberg (1998) and Vikner and Engels (2006). 
In this analysis, the prohibition against object shift without verb movement can essentially be viewed as a kind of anti-locality effect (see also Richards (2004)). More generally, the present approach in terms of relativized cyclic linearization systematically derives a certain class of anti-locality effects (see Grohmann (2003a,b) and Abels (2003)): Whenever a complement $\beta$ of a head $\alpha$ (or some $\gamma$ that is more deeply embedded in $\beta$ but has participated in an ordering statement with $\alpha$ which is still accessible, as in the case just discussed) undergoes feature-driven movement to the specifier of $\alpha$, ungrammaticality arises because of two conflicting linearization statements. Thus, e.g., feature-driven local movement of TP to SpecC across a verb-second head in German (as discussed by Geilfuß (1988), Abels (2003)) will invariably result in ungrammaticality because of two conflicting ordering statements: $\mathrm{C}<$ TP before movement vs. TP $<\mathrm{C}$ after movement; see (35). ${ }^{33}$

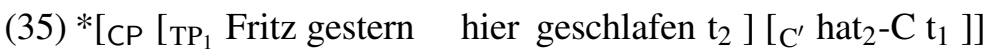
Fritz yesterday here slept has

\subsubsection{Multiple Object Shift}

Multiple object shift, as in the Danish examples involving pronouns in (9), and the Icelandic examples involving non-pronominal DPs in (11), requires verb movement in exactly the same way, and for the same reasons, as simple object shift. In addition, multiple object shift is only possible if the base order among the two objects is maintained (indirect objects uniformly precede direct objects in the base in the Scandinavian languages); compare, e.g., the Icelandic examples in (11-a) and in (11-b), which are repeated here as (36-ab), with relevant structure added.

(36) a. Ég $g_{3}$ lána $\left[\mathrm{vP}_{\mathrm{p}} \mathrm{t}_{3}^{\prime}\left[_{\mathrm{v}^{\prime}}\right.\right.$ Maríu $_{1}\left[_{\mathrm{v}^{\prime}}\right.$ bækurnar $_{2}$

I lend Maria the books

$\left.\left.\left.\left[v^{\prime} \operatorname{ekki}\left[v_{v^{\prime}} t_{3}\left[v^{\prime} t_{V+v}\left[v P t_{1} t_{V} t_{2}\right]\right]\right]\right]\right]\right]\right]$

not

b. *Ég $g_{3}$ lána $\left[{ }_{\mathrm{vP}} \mathrm{t}_{3}^{\prime}\left[_{\mathrm{v}^{\prime}}\right.\right.$ bækurnar $_{2}\left[_{\mathrm{v}^{\prime}}\right.$ Maríu $_{1}$

I lend the books Maria

$\left[v^{\prime}\right.$ ekki $\left.\left.\left.\left[v^{\prime} t_{3}\left[v^{\prime} t_{v+v}\left[v_{P} t_{1} t_{v} t_{2}\right]\right]\right]\right]\right]\right]$

not

\footnotetext{
${ }^{33}$ Needless to say, though, both Grohmann's and Abels' approaches to anti-locality differ significantly from the present approach (and from each other) in their empirical consequences.
} 
The shape conservation effect with multiple feature-driven object movement (for bakurnar 2 and Marí $_{1}$ in (36-ab)) follows without further ado: When $\mathrm{DP}_{1}$ is merged with $\mathrm{V}^{\prime}$ (which includes $\mathrm{DP}_{2}$ ), an ordering statement $\mathrm{DP}_{1}<$ $\mathrm{DP}_{2}$ is generated (because both categories have Merge status $[+\psi]$ ). When $\mathrm{DP}_{1}$ and $\mathrm{DP}_{2}$ undergo object shift to outer specifiers of $\mathrm{v}$, both categories have Merge status $[+\psi]$ again. Since V+v acquires Merge status $[-\psi]$ before object movement (after the external argument $\mathrm{DP}_{3}$ has been merged), there is no linearization problem with respect to verb raising in (36-ab) because $\mathrm{DP}_{1} / \mathrm{DP}_{2}$ and $\mathrm{V}+\mathrm{V}$ do not have the same Merge status (i.e., Holmberg's Generalization is respected). However, there is a linearization issue with $\mathrm{DP}_{1}$ and $\mathrm{DP}_{2}$ : If the two objects reassemble in specifiers of $\mathrm{v}$ in an order that reverses the base order (as in (36-b)), an ordering statement $\mathrm{DP}_{2}<\mathrm{DP}_{1}$ is generated that contradicts the earlier ordering statement $\mathrm{DP}_{1}<\mathrm{DP}_{2}$, which leads to a crash of the derivation. Note that the indirect object $\mathrm{DP}_{1}$ must move first in (36-a), followed by movement of the direct object $\mathrm{DP}_{2}$ to a lower Specv position (tucking in; movement of the subject $\mathrm{DP}_{3}$ may alternatively end up in a higher or lower Specv position, as before, since $\mathrm{DP}_{3}$ has a different Merge status in a derived Specv position: $[-\psi]$ ). In contrast, (36-b) is ungrammatical independently of whether the $\mathrm{DP}_{1}$ or $\mathrm{DP}_{2}$ moves first.

This analysis also explains why a direct object pronoun cannot shift across an indirect object non-pronominal DP; see (10-a) vs. (10-b) in Danish, and (12-a) vs. (12-b) in Icelandic. The latter set of examples is repeated in (37).

$$
\begin{aligned}
& \text { a. *Ég } g_{3} \text { lána }\left[{ } _ { \mathrm { vP } } \mathrm { t } _ { 3 } ^ { \prime } \left[_ { \mathrm { v } ^ { \prime } } \text { bækurnar } _ { 2 } \left[{ } _ { \mathrm { v } ^ { \prime } } \text { ekki } \left[_ { \mathrm { v } ^ { \prime } } \mathrm { t } _ { 3 } \left[{ }_{\mathrm{v}^{\prime}} \mathrm{V}+\mathrm{v}\right.\right.\right.\right.\right. \\
& I \text { lend the books not } \\
& \text { [vP Maríu } \left.\left.\left.\left.\left.\left.{ }_{1}\left[\mathrm{v}^{\prime} \mathrm{t}_{\mathrm{v}} \mathrm{t}_{2}\right]\right]\right]\right]\right]\right]\right] \\
& \text { Maria } \\
& \text { b. Ég } g_{3} \text { lána }\left[{ } _ { v P } t _ { 3 } ^ { \prime } \left[{ } _ { v ^ { \prime } } \text { Maríu } _ { 1 } \left[{ } _ { v ^ { \prime } } \text { ekki } \left[{ } _ { v ^ { \prime } } t _ { 2 } \left[v_{v^{\prime}} V+v\left[v p t _ { 1 } \left[v_{v^{\prime}} t_{v}\right.\right.\right.\right.\right.\right.\right. \\
& \text { I lend Maria not } \\
& \text { bækurnar }_{2} \text { ]]]נ]] } \\
& \text { the books }
\end{aligned}
$$

In both (37-a) and (37-b), an ordering statement $\mathrm{DP}_{1}<\mathrm{DP}_{2}$ is generated when $\mathrm{DP}_{1}$ is first merged. This ordering statement is still visible when object shift applies. This is unproblematic with object shift of $\mathrm{DP}_{1}$ in (37-b) because it generates a new statement $\mathrm{DP}_{1}<\mathrm{DP}_{2}$; but ungrammaticality arises if $\mathrm{DP}_{2}$ undergoes object shift alone, as in (37-a): A new statement $\mathrm{DP}_{2}<\mathrm{DP}_{1}$ is generated, which contradicts the earlier statement $\mathrm{DP}_{1}<\mathrm{DP}_{2}$ that is still accessible. From a more general point of view, movement of $\mathrm{DP}_{2}$ in (37-a) is again too local. If $\mathrm{DP}_{2}$ undergoes topicalization or $w$ h-movement rather 
than object shift in the same context, no problem arises: $\mathrm{DP}_{2}$ then has Merge status $[-\psi]$ in Specv, and consequently does not generate a new ordering statement with respect to $\mathrm{DP}_{1}$. Hence, the wellformedness of examples like (38) in Danish, where a direct object undergoes A-bar movement across an indirect object, is expected. The important fact here is that $\mathrm{DP}_{2}$ does not generate an ordering statement with $\mathrm{DP}_{1}$ when it is merged in the position of $\mathrm{t}_{2}^{\prime}([-\psi]$ vs. $[+\psi])$. Note also that the order of subject $\mathrm{DP}_{3}([-\psi])$ and direct object $\mathrm{DP}_{2}([-\psi])$ is fixed in outer Specv positions here; however, it may be derived either by first moving the subject and then moving the direct object via tucking in, or by first moving the object, and then raising the subject to a higher specifier. ${ }^{34}$

(38) $\left[\mathrm{DP}_{2}\right.$ Denne bog ] viste $\left[\mathrm{TP}_{2} \mathrm{t}_{2}^{\prime \prime}\left[_{\mathrm{T}^{\prime}}\right.\right.$ Peter $_{3} \mathrm{t}_{\mathrm{V}+\mathrm{v}+\mathrm{T}}\left[\mathrm{vvP}_{3} \mathrm{t}_{3}^{\prime}\left[\left[_{\mathrm{v}^{\prime}} \mathrm{t}_{2}^{\prime}\left[\mathrm{v}_{\mathrm{v}^{\prime}}\right.\right.\right.\right.$ ikke this book showed Peter not

$$
\left.\left.\left.\left.\left[v^{\prime} t_{3}\left[v^{\prime} t_{v+v}\left[v P \text { Marie }_{1}\left[v^{\prime} t_{v} t_{2}\right]\right]\right]\right]\right]\right]\right]\right]
$$

Marie

\subsubsection{Pronoun Fronting in German}

One might take the null hypothesis to be that German pronoun fronting is the same kind of operation as Scandinavian object shift. However, there are a number of differences between the two operations, and at least some of these differences shed doubt on such an assumption. A difference that can be accounted for independently is that an unstressed object pronoun may precede a

\footnotetext{
${ }^{34}$ Subject DPs can stay in situ, within the vP, in transitive expletive constructions in Icelandic. Unless further assumptions are made, the present analysis predicts that object shift across the in situ-subject should be impossible. This conforms to observations made in Vikner (1995, 198-200) and Bobaljik and Jonas (1996, 212-214) for non-pronominal DPs (see, e.g., (i)), but is incompatible with the conflicting evidence put forward in Collins $(1997,18)$ and Alexiadou and Anagnostopoulou $(2001,2006)$. It is also incompatible with the evidence from pronominal object shift, which may regularly cross a subject; see Jónsson (1996).

(i) $* \theta$ a $\delta$ lauk verkefninu $2 \quad$ einhver $_{1} \mathrm{t}_{2}$

there finished the assignment someone

For present purposes, I will leave it at that, noting that if object shift across an in situ-subject in transitive expletive constructions turns out to be possible, this could be taken to support the hypothesis that there is overt subject movement in these constructions after all, with the expletive emerging as a partial realization of the moved subject DP, and the putatitive in situ-subject DP emerging as a fully spelled out trace. Needless to say, spell-out of traces would require a further modification of the system developed here, such that linearization is established for three rather than two items as a result of Merge operations.
} 
subject DP in German (cf. (14-c) vs. (14-d)) but not in, say, Danish; this follows straightforwardly from the fact that external arguments are moved to the subject position SpecT optionally in German, and obligatorily in Danish. ${ }^{35}$ Another difference that is not really surprising from the present perspective is that Scandinavian object shift depends on verb movement whereas movement of pronouns in German does not seem to do so in an obvious way (particularly if one assumes that there is no obligatory V-to-T movement in German; see Haider (1993) vs. Sabel (1996)); this simply follows from the assumption that Holmberg's Generalization instantiates a shape conservation effect which cannot show up in the same way in OV languages like German.

However, other asymmetries between Scandinavian object shift and German pronoun fronting are not as readily explained by invoking independent factors. In particular, whereas Scandinavian object shift shows A-movement properties, German pronoun fronting exhibits A-bar movement properties (see Vikner (1994)). Thus, consider the different behaviour with respect to parasitic gap licensing (a typical A-bar movement property) between Danish object shift in (39-a) and German pronoun fronting in (39-b). ${ }^{36}$

(39) a. *Peter inviterede dem ikke $_{1}$ [CP uden at kende $\mathrm{e}_{1}$ på forhånd ] Peter invited them not without to know beforehand

b. dass Peter $\operatorname{sie}_{1}$ [CP ohne $e_{1}$ zu kennen ] $t_{1}$ ins Regal that Peter them without to know into the bookshelf gestellt hat put has

Thus, I would like to conclude (deviating from the set of assumptions in Müller (2001)) that the differences between German pronoun fronting and Scandinavian object shift result from the fact that the two operations have different landing sites: Whereas object shift is feature-driven movement to the specifier of $\mathrm{v}$, pronoun fronting targets a higher functional projection $\mu \mathrm{P}$ that intervenes between TP and vP; A-movement properties are associated with the former position, A-bar movement properties are associated with the

\footnotetext{
${ }^{35}$ However, also cf. Josefsson (1992) on Swedish.

${ }^{36}$ Fanselow $(2001,412)$ argues that the construction in (39-b) does not actually involve a parasitic gap (because it may affect nonreferential and $w h$-pronouns, and may involve multiple gaps), and is hence irrelevant for the question of whether pronoun fronting is an A- or Abar movement operation. Notwithstanding potential empirical problems with some of the relevant data, Fanselow's observations strike me as interesting and may well have interesting consequences for the analysis of, e.g., inherently reflexive verbs in German, but, in my view, they do not call into question a standard parasitic gap analysis.
} 
latter. With this in mind, consider now first derivations of the sentences in (14-c) and (14-d), which are repeated here in (40-ab) (again, with additional structural information). ${ }^{37}$

(40) a. dass $\left[\mathrm{TP}_{\mu \mathrm{P}}{ }_{\mu \mathrm{P}} \mathrm{es}_{1}\left[\mathrm{vp}_{\mathrm{vP}} \mathrm{t}_{1}^{\prime}\left[_{\mathrm{v}^{\prime}}\right.\right.\right.$ gestern ${ }_{\mathrm{v}^{\prime}}\left[\mathrm{DP}_{2}\right.$ der Fritz $]\left[\mathrm{vP}_{1} \mathrm{t}_{1} \mathrm{t}_{\mathrm{V}}[\mathrm{v}\right.$ that it yesterday the Fritz

$[v+v$ gelesen $]]]]]]]$ hat read has

b. dass $\left[\mathrm{TP}_{\mathrm{T}}\left[\mathrm{DP}_{2}\right.\right.$ der Fritz $]\left[_{\mu \mathrm{P}} \mathrm{t}_{2}^{\prime \prime}\left[\mu_{\mu^{\prime}} \mathrm{es}_{1}\left[\mathrm{vP}_{2} \mathrm{t}_{2}^{\prime}\left[\mathrm{v}^{\prime} \mathrm{t}_{1}^{\prime}\left[\mathrm{v}^{\prime}\right.\right.\right.\right.\right.$ gestern $\quad\left[\mathrm{v}^{\prime}\right.$ that the Fritz it yesterday

$\mathrm{t}_{2}\left[\mathrm{vP}_{\mathrm{t}} \mathrm{t}_{\mathrm{v}}[\mathrm{v}[\mathrm{v}+\mathrm{v}\right.$ gelesen $\left.\left.\left.\left.\left.\left.\left.\left.]]\right]\right]\right]\right]\right]\right]\right]\right]$ hat

read has

The only difference between (40-a) and (40-b) is that T has an EPP feature $[\bullet \mathrm{D} \bullet]$ in the latter case, but not in the former (recall that this feature is optional in German). The relevant parts of the derivation of (40-a) proceed as follows: $\mathrm{V}$ obligatorily moves to $\mathrm{v}$ (which is right-peripheral in German), which produces an ordering statement $\mathrm{DP}_{1}<\mathrm{V}+\mathrm{v}$; $\mathrm{DP}_{2}$ is merged in Specv, which generates the ordering statements $\mathrm{DP}_{2}<\mathrm{V}+\mathrm{v}$ and, more relevantly in the present context, $\mathrm{DP}_{2}<\mathrm{DP}_{1}$. After Merge of $\mathrm{DP}_{2}, \mathrm{~V}+\mathrm{v}$ can acquire Merge status $[-\psi]$. However, following essentially Haider (1993), I assume that there is no V-to-T movement (without subsequent T-to-C movement) in German, and so $\mathrm{V}+\mathrm{v}$ continues to have only Merge status $[+\psi]$ here. The next step is movement of $\mathrm{DP}_{1}$ to a specifier of $\mathrm{v}$. Given that pronoun fronting targets $\mathrm{Spec} \mu$, it is clear that $\mathrm{DP}_{1}$ does not undergo feature-driven movement to Specv in (40-a); rather, this movement step is driven by Phase Balance, via the non-local movement-inducing probe feature on $\mu$ in the numeration. Importantly, no new ordering statement $\mathrm{DP}_{1}<\mathrm{DP}_{2}$ is generated because $\mathrm{DP}_{1}$ has Merge status $[-\psi]$, and $\mathrm{DP}_{2}$ has Merge status [+ $\left.\psi\right]$ (there is, by assumption, no $[\bullet \mathrm{D} \bullet]$ feature on $\mathrm{T}$ in the numeration). After the completion of $\mathrm{vP}$, the domain of $\mathrm{V}+\mathrm{v}$ (together with the adverb) is spelled out, and so are the ordering statements generated for this domain. Next, $\mu$ is merged with vP, and $\mathrm{DP}_{1}$ undergoes feature-driven movement to $\mathrm{Spec} \mu$. At this point, a new ordering statement $\mathrm{DP}_{1}<\mu^{\prime}$ is generated (consequently also $\mathrm{DP}_{1}<\mathrm{vP}$, and therefore ultimately $\mathrm{DP}_{1}<\mathrm{DP}_{2}$ ), but this is unproblematic: The earlier linearization statements, including $\mathrm{DP}_{2}<\mathrm{DP}_{1}$, are not syntactically accesible

\footnotetext{
${ }^{37} \mathrm{I}$ assume that the auxiliary in (40) is the head of a $\mathrm{vP}$-external verbal functional projection; but I know of no evidence to decide whether this projection is higher or lower than $\mu \mathrm{P}-$ or, for that matter, identical to it. (For instance, both unstressed pronouns and finite auxiliaries stay behind in predicate ('VP') topicalization contexts.)
} 
anymore on the $\mu \mathrm{P}$ cycle. ${ }^{38}$

As noted, (40-b) differs from (40-a) in having subject raising to SpecT. Thus, both $\mathrm{DP}_{1}$ and $\mathrm{DP}_{2}$ undergo Phase Balance-driven movement to an outer specifier of $v$ in (40-b); since they both have Merge status $[-\psi]$ in the landing site, the two categories have to reassemble in the order dictated by the earlier, still visible, ordering statement, viz., $\mathrm{DP}_{2}<\mathrm{DP}_{1}$. On the $\mu \mathrm{P}$ cycle, both DPs move again to specifier positions; however, no new ordering statement is generated because $\mathrm{DP}_{1}$ has Merge status $[+\psi]$, and $\mathrm{DP}_{2}$ has Merge status $[-\psi]$ (it is required in this position by a non-local feature, viz., $[\bullet \mathrm{D} \bullet]$ on $\mathrm{T}$ in the numeration). Finally, on the TP cycle, $\mathrm{DP}_{2}$ undergoes feature-driven movement to SpecT, and a new ordering statement $\mathrm{DP}_{2}<\mathrm{DP}_{1}$ is generated.

Let us now turn to the case of multiple pronoun fronting in German, as in (15); the examples are repeated here as (41-ab). In this case, there is a shape conservation effect: The subject pronoun must precede the object pronoun in situ and in the ultimate landing site; and, as noted, this cannot be due to obligatory raising to subject position because such raising is optional in German.

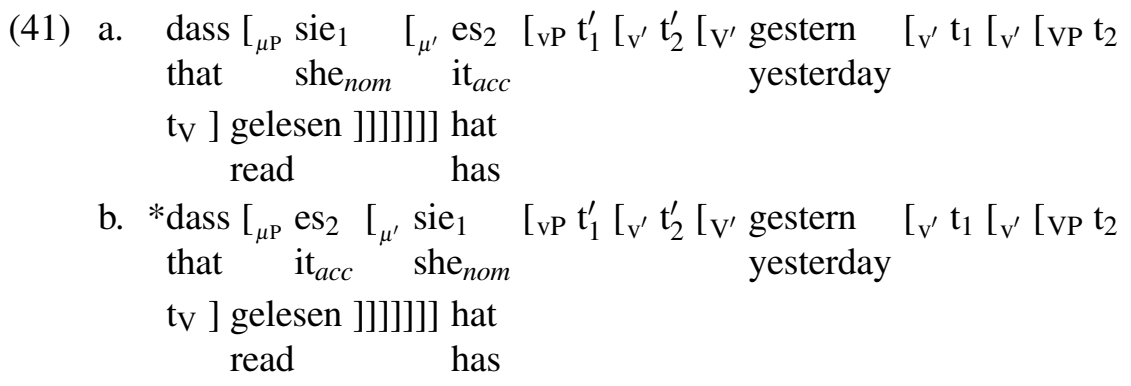

On the vP cycle, when the external argument $\mathrm{DP}_{1}$ is merged, it generates an ordering statement with the internal argument $\mathrm{DP}_{2}$ (among others) because both categories have Merge status [+ $\psi]$ : $\mathrm{DP}_{1}<\mathrm{DP}_{2}$. Next, $\mathrm{DP}_{1}$ and $\mathrm{DP}_{2}$ undergo non-feature-driven movement to outer specifiers of $\mathrm{v}$, forced by Phase Balance via the features on $\mu$ that will later trigger pronoun fronting to this position. Since $\mathrm{DP}_{1}$ and $\mathrm{DP}_{2}$ are both marked $[-\psi]$ after the first movement step, a new ordering statement is generated at a point of the derivation where the original ordering statement is still visible. If $\mathrm{DP}_{1}$ and $\mathrm{DP}_{2}$ reassemble in the pre-movement order, as they do in (41-ab), the new ordering statement is

\footnotetext{
${ }^{38}$ The assumption that pronoun fronting in German is not feature-driven movement to Specv proves crucial here: Otherwise, Merge $\left(\mathrm{DP}_{1}, \mathrm{v}^{\prime}\right)$ would produce a contradictory ordering statement while the original ordering statement is still accessible, and the derivation would be expected to crash.
} 
$\mathrm{DP}_{1}<\mathrm{DP}_{2}$, and no problem arises; if, however, $\mathrm{DP}_{1}$ is moved first, and $\mathrm{DP}_{2}$ then ends up in front of it (or $\mathrm{DP}_{2}$ is moved first, and $\mathrm{DP}_{1}$ is then moved to a lower position, via tucking in), an ordering statement $\mathrm{DP}_{2}<\mathrm{DP}_{1}$ is generated that leads to a crash of the derivation. Exactly the same reasoning applies on the $\mu \mathrm{P}$ cycle, the only difference being that $\mathrm{DP}_{1}$ and $\mathrm{DP}_{2}$ are now both marked $[+\psi]$ again. The (second) ordering statement $\mathrm{DP}_{1}<\mathrm{DP}_{2}$ generated on the vP cycle is still accessible; and therefore this ordering statement demands that the ultimate order of $\mathrm{DP}_{1}$ and $\mathrm{DP}_{2}$ is as in (41-a), and not as in (41-b) (the last step may involve tucking in, but does not have to).

There is an independent piece of evidence for the difference between object shift and pronoun fronting with respect to the landing site. Recall that object shift cannot move an object across another, c-commanding object if it does, a new ordering statement will be generated that contradicts the original one, which is still accessible. If German pronoun fronting does not target Specv (but a higher specifier), the prediction is that an intervening VPinternal object can be crossed in the process; the reason is that an object pronoun that undergoes non-feature-driven movement to Specv $([-\psi])$ does not enter into a new ordering relation with another object that remains in the VP $([+\psi])$. This prediction is borne out: Both a direct object pronoun and an indirect object pronoun can undergo pronoun fronting, with the remaining object staying in situ; see (42-ab). In my view, there is good reason to assume that the base order of arguments in German is neither dative before accusative (as it is standardly assumed, and as it seems correct for the Scandinavian languages), nor variable and dependent on the argument structure of individual verbs (as argued by Haider (2000)), but uniformly (i.e., with all types of verbs) accusative before dative; see Müller $(1993,2001)$ for arguments to this effect. If so, the argument that is crossed by pronoun fronting in (42) is the direct object $\mathrm{DP}_{1}$ (das Buch ('the book')) in (42-b).

(42) a. dass es ${ }_{1}\left[{ }_{\mathrm{vP}} \mathrm{t}_{1}^{\prime}\left[\mathrm{v}^{\prime}\right.\right.$ gestern $\left[\mathrm{v}_{\mathrm{v}^{\prime}}\right.$ die Maria $\left[\mathrm{vP} \mathrm{t}_{1}\left[\mathrm{v}^{\prime}{ }_{\mathrm{DP}_{2}}\right.\right.$ dem that it $_{\text {acc }}$ yesterday the Maria ${ }_{n o m}$ the

Karl ] $t_{V}$ ] gegeben ]]] hat

$\mathrm{Karl}_{\text {dat }}$ given has

b. dass $\mathrm{hhm}_{2}\left[\mathrm{vp}_{2}^{\prime}\left[\mathrm{v}^{\prime}\right.\right.$ gestern $\left[\mathrm{v}^{\prime}\right.$ die Maria $\left[\mathrm{vP}\left[\mathrm{DP}_{1}\right.\right.$ das that $\operatorname{him}_{\text {dat }} \quad$ yesterday the Marianom the

Buch ] [ $\mathrm{v}^{\prime} \mathrm{t}_{2}$ gegeben $\left.\left.\left.]\right]\right]\right]$ hat ]

book $_{a c c}$ given has

Finally, given a uniform base order accusative before dative, we expect that if both objects are unstressed pronouns, they have to show up in exactly this 
order after pronoun fronting. Again, the prediction is confirmed: The order of direct and indirect pronouns after multiple fronting must be accusative before dative; see (43-a) vs. (43-b). ${ }^{39}$

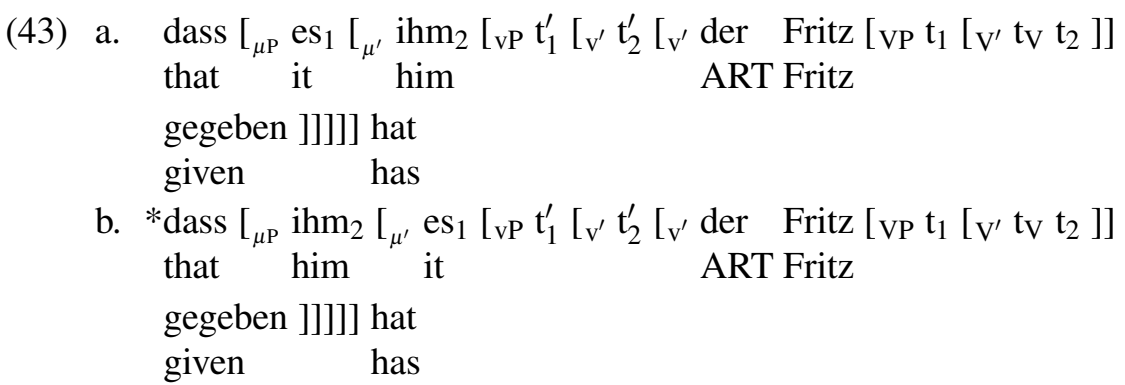

The analysis is almost exactly as in (41), where one pronoun is a subject and one an object: After Merge of the accusative object $\mathrm{DP}_{1}$, a linearization statement is generated that includes the dative object $\mathrm{DP}_{2}: \mathrm{DP}_{1}<\mathrm{DP}_{2}$. Since both pronouns first undergo non-feature-driven movement to an outer specifier of $\mathrm{v}$, and consequently they both acquire Merge status $[-\psi]$ as a result of the movement operations, a new ordering statement for $\mathrm{DP}_{1}$ and $\mathrm{DP}_{2}$ is generated. If the order in the edge domain of $\mathrm{v}$ is $\mathrm{DP}_{2}<\mathrm{DP}_{1}$, the derivation crashes at this point. In (43-ab), however, the original order is maintained, and a new ordering statement $\mathrm{DP}_{1}<\mathrm{DP}_{2}$ is generated that is compatible with the older one. The same reasoning applies on the next, and final, cycle, viz., $\mu \mathrm{P}$. Now both pronouns have Merge status $[+\psi]$, and a new ordering statement is generated while the ordering statement from the edge domain of $\mathrm{vP}$ is still accessible. In (43-b), a contradictory statement is generated, with ungrammaticality resulting; in (43-a), the previous order is maintained, and a non-contradictory ordering statement is generated.

Taking together the analyis of examples with two object pronouns, and of examples with a subject and a (direct) object, the prediction is that there is an obligatory order subject before direct object before indirect object in examples with three unstressed pronouns. This is borne out.

\footnotetext{
${ }^{39}$ There are a few complications. One concerns the order of pronouns in coherent infinitive constructions, where the expected linearization shows up but might initially be unexpected in some cases (assuming that two clauses are involved); see Müller (2001). Other complications involve deviations from the expected order in certain contexts, which may show the influence of other factors on the order of unstressed pronouns. See Zifonun et al. (1997) (and literature cited there) and Anagnostopoulou (2005).
} 


\subsubsection{Multiple Wh-Movement in Bulgarian}

The account of the shape conservation effect with multiple $w h$-movement in Bulgarian that can be given in the present approach is completely parallel to the account of multiple pronoun fronting in German. ${ }^{40}$ The relevant examples are repeated here from (16).

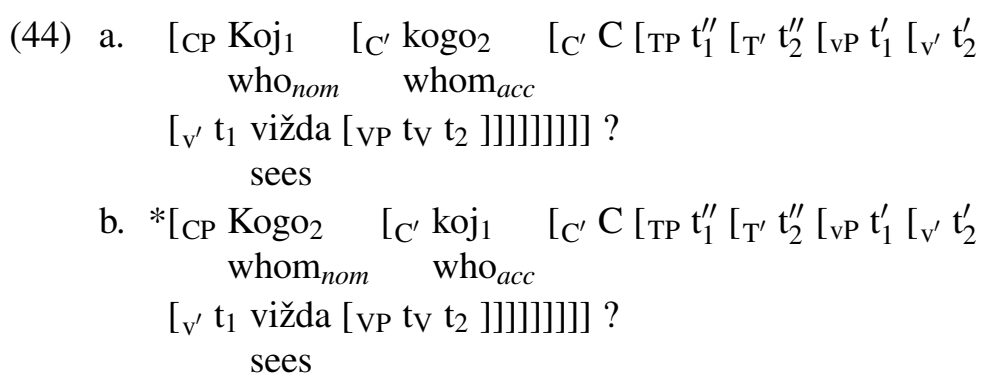

As before, when the external argument $\mathrm{DP}_{1}$ is merged with $\mathrm{v}^{\prime}$, an ordering statement $\mathrm{DP}_{1}<\mathrm{DP}_{2}$ is generated (because at this point, both categories have Merge status $[+\psi]$ ). Next, Phase Balance forces both DPs to undergo non-feature-driven movement to an outer specifier of $\mathrm{v}$, and since the DPs both have Merge status $[-\psi]$ in this position (and therefore give rise to a new ordering statement), they must show up in the pre-movement order in the edge domain of $\mathrm{vP}$. On the TP cycle, the same reasoning applies, and $\mathrm{DP}_{1}$ and $\mathrm{DP}_{2}$ must again show up in the original order $\left(\mathrm{DP}_{1}\right.$ is $[-\psi]$ in SpecT even if $\mathrm{T}$ has a $[\bullet \mathrm{D} \bullet]$ feature, given that $\mathrm{C}-$ which is still in the numeration - has

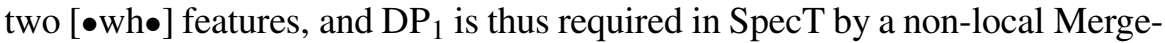
inducing feature). Finally, on the $\mathrm{CP}$ cycle, both categories have reached their ultimate landing site; they have Merge status $[+\psi]$, which again generates an ordering statement, which must then not contradict the earlier ordering statement on the TP cycle which is still accessible. In principle, this mechanism is unbounded: Whenever two categories end up in the same edge domain as a result of non-feature-driven movement, they must respect an original order determined by external Merge, and they will have to preserve that order in all subsequent cycles (with the derivation proceeding via tucking in) until either both reach their target position on the same cycle (then the original order must be maintained here as well), or one reaches its ultimate landing site and the other one moves on (then the original order can be reversed because no new statement is generated, and the earlier statements are now inaccessible in the derivation).

\footnotetext{
${ }^{40}$ Recall, however, that things are less clear with two wh-objects.
} 


\subsubsection{A-Movement in Passive and Raising Constructions}

Recall that A-movement constructions like those in (17) pose a problem for Fox and Pesetsky's approach if unaccusative and passive vPs have phase (spell-out domain) status; see (45-ab).

(45) a. [СР C [TP John ${ }_{1}$ was $\left[\mathrm{vP} \mathrm{t}_{1}^{\prime}\left[\mathrm{v}^{\prime}\right.\right.$ hit-v [ $\left.\left.\left.\mathrm{t} \mathrm{t}_{1}\right]\right]\right]$

b. [СР C [тр Mary 1 T [vP seems-v [Tе $\mathrm{t}_{1}$ to be smart ]]]]

There is no problem in deriving these examples in the present approach. When $\mathrm{V}$ is moved to $\mathrm{v}$, an ordering statement $\mathrm{V}+\mathrm{v}<\mathrm{DP}_{1}$ is generated. Next, $\mathrm{DP}_{1}$ moves to Specv because of Phase Balance. Since this movement is not feature-driven, $\mathrm{DP}_{1}$ now has Merge status $[-\psi] . \mathrm{V}+\mathrm{v}$ does not have to move on the next cycle, so it continues to have only Merge status $[+\psi]$; hence, no new ordering statement is generated. After this, $\mathrm{T}([+\psi])(=$ was $)$ is merged with $\mathrm{vP}$. This generates ordering statements (with $\mathrm{vP}$ and $\mathrm{V}+\mathrm{v}$ ), but not with $\mathrm{DP}_{1}([-\psi])$. Finally, on the TP cycle $\mathrm{DP}_{1}$ undergoes feature-driven movement to SpecT. This generates an ordering statement $\mathrm{DP}_{1}<\mathrm{T}^{\prime}$, which does not contradict any earlier ordering statement that would still be visible.

\subsubsection{Verb-Second}

The final two constructions to be addressed here involve verb-second in SVO languages and verb-second in SOV languages. Both constructions raise problems for the approach in Fox and Pesetsky (2005a) but turn out to be fully compatible with the present, relativized approach to cyclic linearization.

Consider first verb-second in an SVO language like Danish, as exemplified by the sentences in (13-b) $(=(33))$ and (38); the former is repeated here as (46). Recall that the main problem with verb-second in SVO languages in Fox and Pesetksky's approach is that an order of subject before verb can be changed into an order of verb before subject. ${ }^{41}$
(46) $\left[\mathrm{CP}\right.$ Hvorfor $\left[\left[_{\mathrm{C}^{\prime}}\left[{ }_{\mathrm{v}+\mathrm{v}+\mathrm{T}+\mathrm{C}}\right.\right.\right.$ købte $]\left[\mathrm{TPP}\right.$ Peter $_{2}\left[_{\mathrm{T}^{\prime}} \mathrm{t}_{\mathrm{v}+\mathrm{v}+\mathrm{T}}\left[{ }_{\mathrm{vP}} \mathrm{t}_{2}^{\prime}\left[_{\mathrm{v}^{\prime}} \operatorname{den}_{1}\left[\left[_{\mathrm{v}^{\prime}}\right.\right.\right.\right.\right.$ why bought Peter it ikke $\left.\left.\left.\left.\left.\left.\left[{ }_{v^{\prime}} t_{2}\left[{ }_{v^{\prime}} t_{V+v}\left[v_{P} t_{V} t_{1}\right]\right]\right]\right]\right]\right]\right]\right]\right]$ ?
not

We can abstract away from all ordering statements involving the object pronoun because this issue has already been discussed in section 5.2.4. Fo-

\footnotetext{
${ }^{41}(33)$ has been analyzed in the present approach already, but only with respect to the interaction of the two DPs; now the focus is on the relation of the verb and the subject DP.
} 
cussing on the verb and the external argument $\mathrm{DP}_{2}$, an ordering statement $\mathrm{DP}_{1}<\mathrm{V}+\mathrm{v}$ is generated when the external argument is merged with $\mathrm{v}^{\prime}$. Next (after its subcategorization probe features have been discharged), $\mathrm{V}+\mathrm{v}$ acquires Merge status [- $\psi]$, and $\mathrm{DP}_{2}$ undergoes non-feature-driven movement to an outer specifier because of Phase Balance, thereby acquiring Merge status $[-\psi]$. A second, identical ordering statement for $\mathrm{DP}_{2}$ and $\mathrm{V}+\mathrm{v}$ is thus generated on the $\mathrm{vP}$ cycle. On the TP cycle, note first that no ordering statement is generated for $\mathrm{T}([+\psi])$ and $\mathrm{DP}_{2}([-\psi])$. Next, $\mathrm{V}+\mathrm{v}$ moves to $\mathrm{T}$; $\mathrm{V}+\mathrm{v}+\mathrm{T}$ acquires Merge status $[-\psi]$ since $\mathrm{T}$ has used up its subcategorization probe features but is needed by a probe feature triggering verb-second movement that is located on $\mathrm{C}$ in the numeration. After this, $\mathrm{DP}_{2}$ moves to SpecT, obtaining Merge status $[+\psi]$. Consequently, no new ordering statement is generated for subject and verb. Next, the domain of $\mathrm{T}$ is spelled out, which removes all existing ordering statements for subject and verb from the syntactic derivation. Finally, $\mathrm{T}$ moves to $\mathrm{C}$. This generates a new ordering statement $\mathrm{V}+\mathrm{v}+\mathrm{T}+\mathrm{C}<\mathrm{DP}_{1}$ (since both categories are now marked $[+\psi]$ ), which contradicts the earlier statement $\mathrm{DP}_{1}<\mathrm{V}+\mathrm{v}$. However, by the time the new statement is generated by the derivation, the earlier, contradictory statement has been removed from it.

Consider finally verb-second in SOV languages. This construction has resisted a simple analysis in Fox and Pesetsky's approach because the order of an argument (in particular, an object) and the verb may be systematically reversed from the lower spell-out domain to the higher spell-out domain; recall the examples in (20), the first of which is repeated here with additional structural information.

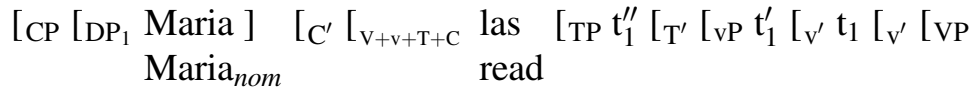

$$
\begin{aligned}
& \text { [DP } \left.\left.\left.\left.\left.\left.\left.\left.2 \text { das Buch ] } t_{\mathrm{V}}\right] \mathrm{t}_{\mathrm{V}+\mathrm{v}}\right]\right] \mathrm{t}_{\mathrm{V}+\mathrm{v}+\mathrm{T}}\right]\right]\right]\right]\right] \\
& \text { the } \text { book }_{a c c}
\end{aligned}
$$

When $\mathrm{V}$ is moved to $\mathrm{v}$, an ordering statement $\mathrm{DP}_{2}<\mathrm{V}+\mathrm{v}$ is generated. Next, $\mathrm{DP}_{1}$ is merged with $\mathrm{v}^{\prime}$, which results in (among others) the ordering statements $\mathrm{DP}_{1}<\mathrm{V}+\mathrm{v}$ and $\mathrm{DP}_{1}<\mathrm{DP}_{2}$. Then $\mathrm{DP}_{1}$ undergoes string-vacuous, non-feature-driven movement to an outer specifier of $\mathrm{v}$ because Phase Bal-

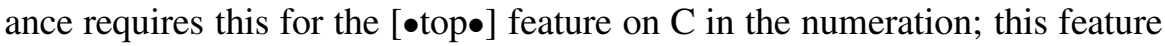
acts as the trigger for topicalization. ${ }^{42}$ Since $\mathrm{V}+\mathrm{v}$ is $[-\psi]$ by now (v has dis-

\footnotetext{
${ }^{42}$ We can assume that $\mathrm{DP}_{1}$ has a matching [top] feature; alternatively, it might be that $\mathrm{C}$ 's relevant feature is a bare EPP feature in the case at hand, and minimality requirements then force movement of the highest argument. See Fanselow and Mahajan (2000), Fanselow
} 
charged its arguments and is required in its position by a non-local feature on $\mathrm{C}$ in the numeration), a new statement $\mathrm{DP}_{1}<\mathrm{V}+\mathrm{v}$ is generated that corresponds to the one established earlier. After this, the the verb and the subject argument move up hand in hand in the structure, generating identical ordering statements with respect to each other, until $\mathrm{T}$ ends up in $\mathrm{C}$, and $\mathrm{DP}_{1}$ undergoes feature-driven movement to SpecC. At this point, both $\mathrm{V}+\mathrm{v}+\mathrm{T}+\mathrm{C}$ and $\mathrm{DP}_{1}$ are $[+\psi]$, and a final compatible ordering statement is generated $\left(\mathrm{DP}_{1}\right.$ $<\mathrm{T})$. As for the relation of the verb and the object $\mathrm{DP}_{2}$, the initial linearization statement $\mathrm{DP}_{2}<\mathrm{V}+\mathrm{v}$ is not followed by any other statement involving these two categories after the $\mathrm{vP}$ cycle is completed. When $\mathrm{V}+\mathrm{v}+\mathrm{T}$ moves to $\mathrm{C}$, it generates a new ordering statement with $\mathrm{TP}$ - hence ultimately, at $\mathrm{PF}$, with the object $\mathrm{DP}_{2}$, via the Nontangling Condition. However, $\mathrm{DP}_{2}$ has already undergone spell-out as part of the domain of $\mathrm{v}$ after $\mathrm{vP}$ is completed. Thus, whereas the verb follows the object at the beginning of the derivation, it precedes the object at the end of the derivation. This is entirely unproblematic because thanks to the fact that phases are small units in the present approach, the window in which ordering statements are accessible is fairly small throughout the derivation; and by the time the CP cycle is reached, all ordering statements of the vP cycle which have not been constantly renewed throughout the derivation by multiple non-feature-driven movement to edge domains are irrelevant for syntactic operations. ${ }^{43}$

\subsubsection{Scrambling}

The question arises of how order-changing scrambling fits into the approach to relativized cyclic linearization outlined here. Given that some notion of shape conservation plays a role for syntactic movement operations, orderchanging scrambling can be viewed as initially unexpected; and it does indeed turn out that the present approach is incompatible with many theories of scrambling. ${ }^{44}$ It is incompatible with the assumption that scrambling is local, feature-driven movement to Specv; as has been amply illustrated above, local movement to Specv obeys shape conservation (an object can never be crossed by another object, and subject DPs can stay in situ, within vP, in German, in

(2003), and Fanselow and Lenertová (2007) for relevant discussion.

${ }^{43} \mathrm{As}$ far as object-initial verb-second clauses are concerned (see (20-c)), the derivation is straightforward in SVO and SOV languages: When an object DP moves to Specv because of Phase Balance, an ordering statement DP $>\mathrm{V}+\mathrm{v}$ is established because both items are $[-\psi]$ at this point, and this order is then maintained throughout the derivation, including the final landing sites, where both items are $[+\psi]$.

${ }^{44}$ Incidentally, this does not hold for Fox and Pesetsky's (2005a) approach. 
which case they block feature-driven movement of an object to Specv). The present approach is also incompatible with the hypothesis that scrambling in German and other languages is base-generated, i.e., that there is no fixed base order (see, e.g., Haider (1988), Fanselow (2001)); the reason is that the shape conservation effects with pronoun fronting can only be derived by cyclic linearization if there is a fixed base order.

What, then, could be possible approaches to scrambling that are compatible with relativized cyclic linearization? Perhaps the most straightforward possibility would be to assume that scrambling targets unique specifiers of functional categories (and not multiple specifiers); see, e.g., Meinunger (1995). These functional categories must be located above vP, but below $\mu \mathrm{P}$ (because all scrambled material follows all unstressed pronouns). Another approach might try to assign scrambled items a special Merge status that would systematically prevent the generation of ordering statements by Merge (and that might treat scrambled items on a par with adverbial categories). Third, it might be a constitutive property of scrambling that this movement operation deletes existing ordering statements. And fourth, a more radical approach might directly take into account that it has sometimes been argued that a reversal of the pre-movement order is in fact the very reason for the existence of scrambling (see, e.g., Ross (1967), Haider (1993)). On this view, a scrambling operation might apply in order to yield contradictory ordering statements; a technical implementation of this idea might then involve concepts like constraint ranking and constraint violability. I will have to leave these questions open.

\section{Conclusion}

To sum up, the present system of relativized cyclic linearization predicts two kinds of shape conservation effects. First, there are anti-locality effects: Two conflicting ordering statements arise for a head an an XP within the same phase; this effect is instantiated by simple object shift that is not accompanied by verb movement out of the vP. Second, there are multiple movement effects: These involve two items that originate in the same domain, undergo successive-cylic, non-feature-driven movement together, and finally end up in the same domain again, as is the case with multiple object shift, multiple pronoun fronting, and multiple $w h$-movement. The analysis relies on a derivational organization of grammar where (i) information is lost as the derivation proceeds; (ii) the role of representations is minimized (ordering statements are generated for structure-building operations, not for represen- 
tations); and (iii) intermediate movement steps can be formally distinguished from final movement steps.

\section{References}

Abels, Klaus

2003 Successive Cyclicity, Anti-Locality, and Adposition Stranding. Ph.D.

Adger, David thesis, University of Connecticut, Storrs, Connecticut.

2003 Core Syntax. Oxford University Press, Oxford, New York.

Agbayani, Brian

1998 Feature Attraction and Category Movement. Ph.D. thesis, UC Irvine.

Alexiadou, Artemis

1997 Adverb Placement. Benjamins, Amsterdam.

Alexiadou, Artemis and Elena Anagnostopoulou

2001 The subject in situ generalization, and the role of Case in driving

computations. Linguistic Inquiry, 32: 193-231.

2006 The subject in situ generalization revisited. Ms., Universität Stuttgart and University of Crete. This volume.

Anagnostopoulou, Elena

2005 Judgements on pronoun restrictions in German. Ms., University of Crete.

Baker, Mark

1988 Incorporation. A Theory of Grammatical Function Changing. Uni-

Bierwisch, Manfred versity of Chicago Press, Chicago.

1963 Grammatik des deutschen Verbs. Studia Grammatica II. Akademie Verlag, Berlin.

Billings, Loren and Catherine Rudin

1996 Optimality and superiority: A new approach to overt multiple wh ordering. In Jindřich Toman, (ed.), Proceedings of Formal Approaches to Slavic Linguistics. The College Park Meeting 1994, pp. 35-60. Ann

Biskup, Petr Arbor.

2005 Phase featuring. Ms., Universität Leipzig.

Bobaljik, Jonathan

2002 A-chains at the PF interface. Natural Language and Linguistic The-

ory, 20: 197-267.

2005 Re: Cyclin and the role of PF in object shift. Theoretical Linguistics, 31: $111-125$.

Bobaljik, Jonathan and Dianne Jonas

1996 Subject positions and the roles of tp. Linguistic Inquiry, 27: 195-236.

Boeckx, Cedric

2003 Islands and Chains. Resumption as Stranding. Benjamins, Amsterdam.

Bošković, Željko

2002a A-movement and the EPP. Syntax, 5: 167-218.

2002b On multiple wh-fronting. Linguistic Inquiry, 33: 351-383. 
Chomsky, Noam

1973 Conditions on transformations. In Stephen Anderson and Paul Kiparsky, (eds.), A Festschrift for Morris Halle, pp. 232-286. Academic Press, New York.

1981 Lectures on Government and Binding. Foris, Dordrecht.

1986 Barriers. MIT Press, Cambridge, Mass.

1993 A minimalist program for syntactic theory. In Ken Hale and Samuel Jay Keyser, (eds.), The View from Building 20, pp. 1-52. MIT Press, Cambridge, Mass.

1995 The Minimalist Program. MIT Press, Cambridge, Mass.

2000 Minimalist inquiries: The framework. In Roger Martin, David Michaels, and Juan Uriagereka, (eds.), Step by Step, pp. 89-155. MIT Press, Cambridge, Mass.

2001a Beyond explanatory adequacy. Ms., MIT, Cambridge, Mass.

2001b Derivation by phase. In Michael Kenstowicz, (ed.), Ken Hale. A Life in Language, pp. 1-52. MIT Press, Cambridge, Mass.

2005a On phases. Ms., MIT, Cambridge, Mass.

2005b Three factors in language design. Linguistic Inquiry, 36: 1-22.

Cinque, Guglielmo

1999 Adverbs and Functional Heads. Oxford University Press, Oxford.

Collins, Chris

1997 Local Economy. MIT Press, Cambridge, Mass.

2003 Eliminating labels. In Samuel David Epstein and T. Daniel Seely, (eds.), Derivation and Explanation in the Minimalist Program, pp. 42-64. Blackwell, Oxford.

Collins, Chris and Höskuldur Thráinsson

1996 VP-internal structure and object shift in Icelandic. Linguistic Inquiry, 27: 391-447.

Epstein, Samuel David and T. Daniel Seely

2002 Rule applications as cycles in a level-free syntax. In Samuel David Epstein and T. Daniel Seely, (eds.), Derivation and Explanation in the

Fanselow, Gisbert Minimalist Program, pp. 65-89. Blackwell, Oxford.

1991 Minimale syntax. Habilitation thesis, Universität Passau.

2001 Features, theta-roles, and free constituent order. Linguistic Inquiry,

32: 405-436.

2003 Münchhausen-style head movement and the analysis of verb-second. In Anoop Mahajan, (ed.), Head Movement and Syntactic Theory, volume 3 of Syntax at Sunset, pp. 40-76. UCLA \& Universität Potsdam Working Papers in Linguistics, Los Angeles \& Potsdam.

Fanselow, Gisbert and Denisa Lenertová

2007 Movement to Spec,CP and linearization. Ms., Universität Potsdam \& Universität Leipzig.

Fanselow, Gisbert and Anoop Mahajan

2000 Towards a minimalist theory of wh-expletives, wh-copying, and successive cyclicity. In Uli Lutz, Gereon Müller, and Arnim von Stechow, (eds.), Wh-Scope Marking, pp. 195-230. Benjamins, Amsterdam. 
Fischer, Silke

2004 Towards an Optimal Theory of Reflexivization. Ph.D. thesis, Universität Tübingen.

Fox, Danny and David Pesetsky

2003 Cyclic linearization and the typology of movement. Ms., MIT (long

2005a handout).

2005a Cyclic linearization of syntactic structure. Theoretical Linguistics,

2005b Cyclic linearization and its interaction with other aspects of grammar: A reply. Theoretical Linguistics, 31: 235-262.

Frampton, John and Sam Gutman

1999 Cyclic computation. Syntax, pp. 1-27.

Gärtner, Hans-Martin

2002 Generalized Transformations and Beyond. Akademie-Verlag, Berlin.

Gazdar, Gerald

1981 Unbounded dependencies and coordinate structure. Linguistic Inquiry, 12: 155-184.

Gazdar, Gerald, Ewan Klein, Geoffrey Pullum, and Ivan Sag

1985 Generalized Phrase Structure Grammar. Blackwell, Oxford.

Geilfuß, Jochen

1988 Reanalyse? Master's thesis, Universität Tübingen.

Grewendorf, Günther

$2001 \quad$ Multiple wh-fronting. Linguistic Inquiry, 32: 87-122.

Grohmann, Kleanthes

2003a Prolific Domains: On the Anti-Locality of Movement Dependencies. John Benjamins, Amsterdam \& Philadelphia.

2003b Successive cyclicity under (anti-)local considerations. Syntax, 6:

Haider, Hubert 260-312.

1988 Theta-tracking systems - evidence from German. In Laszlo Marácz and Pieter Muysken, (eds.), Configurationality, pp. 185-206. Foris,

1993 Dordrecht.

2000 Beutsche Syntax-generativ. Narr, Tubingen. Jane Grimshaw, (eds.), Lexical Specification and Insertion, pp. 135-

Hallman, Peter 164. Benjamins, Amsterdam.

2000 Verb-final as a subcase of verb-second. In M. Hirotani, A. Coetzee, N. Hall, and J.-Y. Kim, (eds.), Proceedings of NELS 30, pp. 287-298.

Heck, Fabian GLSA, Amherst, Mass.

2004 A Theory of Pied Piping. Ph.D. thesis, Universität Tübingen.

2005 Remarks on Fox \& Pesetsky (2003). Lecture Notes, Universität Leipzig.

Heck, Fabian and Gereon Müller

$2000 \quad$ Successive cyclicity, long-distance superiority, and local optimization. In Roger Billerey and Brook D. Lillehaugen, (eds.), Proceedings of WCCFL, volume 19, pp. 218-231. Cascadilla Press, Somerville, MA. 
2006a Derivational optimization of wh-movement. Ms., Universität Leipzig. To appear in special issue of Linguistic Analysis: Dynamic Interfaces;

2006b Extremely local optimization. Ms., Universität Leipzig.

Heidolph, Karl Erich, Walter Flämig, and Wolfgang Motsch

1981 Grundzüge einer deutschen Grammatik. Akademie-Verlag, Berlin.

Holmberg, Anders

1986 Word Order and Syntactic Features in the Scandinavian Languages

and English. Ph.D. thesis, University of Stockholm.

1998 Remarks on Holmberg's Generalization. Studia Linguistica, 53: 139.

Ishihara, Shinichiro

2004 Prosody by phase. Ms., Universität Potsdam.

Johnson, Kyle

1991 Object positions. Natural Language and Linguistic Theory, 9: 577636.

Jónsson, Jóhannes Gísli

1996 Clausal Architecture and Case in Icelandic. Ph.D. thesis, University Josefsson, Gunlög of Massachusetts, Amherst.

1992 Object shift and weak pronominals in Swedish. Working Papers in

Kayne, Richard Scandinavian Syntax, 49: 59-94.

1994 The Antisymmetry of Syntax. MIT Press, Cambridge, Mass.

Ko, Heejeong

2004 Asymmetries in scrambling and cyclic linearization. Ms., MIT, Cam-

Kobele, Greg

2006 Generating Copies. Ph.D. thesis, UCLA, Los Angeles.

Koster, Jan

$1978 \quad$ Locality Principles in Syntax. Foris, Dordrecht.

2000 Variable-free grammar. Ms., University of Groningen.

Kratzer, Angelika and Lisa Selkirk

2007 Phase theory and prosodic spellout: The case of verbs. Ms., University of Massachusetts, Amherst.

Legate, Julie Anne

2003 Some interface properties of the phase. Linguistic Inquiry, 34: 506-

Lenerz, Jürgen 516.

1977 Zur Abfolge nominaler Satzglieder im Deutschen. Narr, Tübingen.

McCloskey, James

2002 Resumptives, successive cyclicity, and the locality of operations. In Samuel David Epstein and T. Daniel Seely, (eds.), Derivation and Explanation in the Minimalist Program, pp. 184-226. Blackwell, Oxford.

Meinunger, André

1995 Discourse Dependent DP (De-)Placement. Ph.D. thesis, Universität Potsdam. 
Müller, Gereon

1993 On Deriving Movement Type Asymmetries. Ph.D. thesis, Universität Tübingen.

2000 Shape conservation and remnant movement. In M. Hirotani, A. Coetzee, N. Hall, and J.-Y. Kim, (eds.), Proceedings of NELS 30, pp. 525539. GLSA, Amherst, Mass. Revised and extended version appeared 2002 in Artemis Alexiadou, Elena Anagnostopoulou, Sjef Barbiers, \& Hans-Martin Gärtner (eds.), Dimensions of Movement, 209-241. Amsterdam: Benjamins.

2001 Order preservation, parallel movement, and the emergence of the unmarked. In Géraldine Legendre, Jane Grimshaw, and Sten Vikner, (eds.), Optimality-Theoretic Syntax, pp. 279-313. MIT Press, Cambridge, Mass.

2004 Phrase impenetrability and wh-intervention. In Arthur Stepanov, Gisbert Fanselow, and Ralf Vogel, (eds.), Minimality Effects in Syntax, pp. 289-325. Mouton de Gruyter, Berlin.

2005 Remarks on cyclic linearization and order preservation. Theoretical Linguistics, 31: 159-171.

Müller, Gereon and Wolfgang Sternefeld

1993 Improper movement and unambiguous binding. Linguistic Inquiry,

Nilsen, Øystein 24: 461-507.

2005 Some notes on cyclic linearization. Theoretical Linguistics, 31: 173183.

Partee, Barbara, Alice ter Meulen, and Robert Wall

1993 Mathematical Methods in Linguistics. Kluwer, Dordrecht.

Pesetsky, David

1982 Paths and Categories. Ph.D. thesis, MIT, Cambridge, Mass.

Richards, Marc

2004 Object Shift and Scrambling in North and West Germanic: A Case

Richards, Norvin

Study in Symmetrical Syntax. Ph.D. thesis, University of Cambridge, Cambridge, UK.

$2001 \quad$ Movement in Language. Oxford University Press, Oxford.

Rizzi, Luigi

1990 Relativized Minimality. MIT Press, Cambridge, Mass.

Roberts, Ian

1991 Excorporation and minimality. Linguistic Inquiry, 22: 209-218.

Roberts, Ian and Anna Roussou

2002 The extended projection principle as a condition for the tensedependency. In Peter Svenonius, (ed.), Subjects, Expletives, and the EPP. Benjamins, Amsterdam.

Ross, John

1967 Constraints on Variables in Syntax. Ph.D. thesis, MIT, Cambridge, Mass.

Rudin, Catherine

1988 On multiple questions and multiple wh fronting. Natural Language and Linguistic Theory, 6: 445-501. 


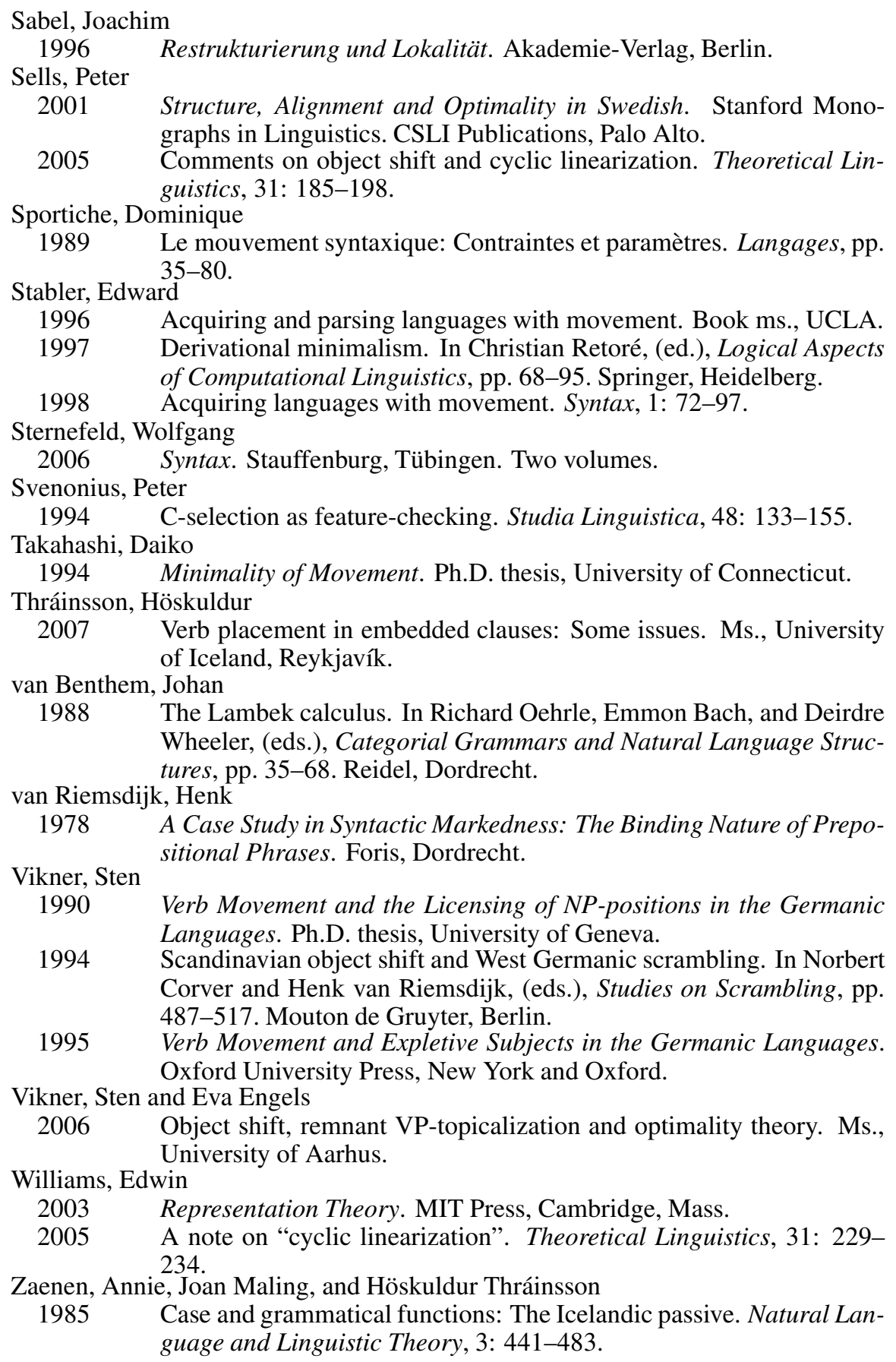


Zifonun, Gisela, Ludger Hoffmann, Bruno Strecker, et al.

1997 Grammatik der deutschen Sprache. de Gruyter, Berlin.

Zwart, Jan-Wouter

1993 Dutch Syntax. A Minimalist Approach. Ph.D. thesis, Rijkuniversiteit Groningen. 